\title{
HISTORIAS DE VIDA
}

\section{LA PRAXEOLOGÍA EN EL AULA DE CLASE \\ Por: Carlos Alberto González Pulido ${ }^{5}$}

$\mathrm{L}^{2}$ a vida del maestro está permeada por una variada gama de fenómenos interactuantes en el desarrollo de una responsabilidad social, lo convoca en relación con unos ideales, con un contexto cercano y un estilo de país que lo afectan en el logro de sus anhelos, allí se entrelazan las diferentes formas de ser y pensar desde nuestro rol profesional motivando permanentes reflexiones en nuestro caminar.

Esta invitación para realizar un viaje a través de las prácticas en el desempeño docente, induce al reconocimiento de las experiencias, valorando los aportes en la transformación individual y colectiva, sus perspectivas, problemáticas y proyecciones.

En ese contexto, mi práctica docente puede ser vista en dos momentos, el primero, un desempeño sin la formación pedagógica, donde la preocupación estaba centrada en trabajar desde unos contenidos curriculares específicos, planeados al comenzar el año académico y que sustentaban el desarrollo de las clases desde una normatividad vigente. Un segundo momento tiene que ver con el ejercicio profesional después de obtener la Licenciatura en Educación, donde se fortaleció tanto la fundamentación conceptual como la implementación de estrategias metodológicas acordes con el perfil, las necesidades de los estudiantes, la intencionalidad de las temáticas y el sentido teleológico pensado desde la institución educativa.

$\mathrm{Al}$ evocar la vinculación inicial a la docencia en el municipio de Quipile, Cundinamarca, vereda El Retiro, en la década del ochenta, predominaba la orientación educativa dada desde la Misión alemana, con el apoyo de libros de texto que servían de guía para el desarrollo de las clases, dentro de un sistema de planeación definido por el gobierno nacional. La parcelación para cada una de los temas era revisada previamente cada semana por el director de la escuela de la época y contaba con su aprobación para ser luego llevada al aula de clase. Por tanto, el "cuaderno parcelador" se constituía en el instrumento guía del docente, que debía ser cumplido con gran cuidado, teniendo en cuenta que el Director podía revisar los cuadernos de los estudiantes, en cualquier momento, para evidenciar el avance en los temas previamente establecidos.

Allí era indispensable el diálogo constante con los vecinos, con la Junta de Acción Comunal, con el Inspector de Policía, ellos conocían de primera mano las necesidades de la comunidad, eran las personas que más interactuaban y contribuían con la escuela. Por tanto con ellos se discutían algunas actividades de interés común para los padres de familia, la vereda, la realización de algunas obras y la disponibilidad de recursos. Ellos evaluaban la gestión de la escuela y sus docentes.

La escuela en mención había sido construida por la Federación Nacional de Cafeteros, se llegaba por dos caminos, en ambos casos distantes de la carretera intermunicipal por más de hora y media de recorrido a pie, bajo un sol agotador. Tres docentes atendíamos cerca de 90 estudiantes de educación básica primaria, distribuidos en dos salones y un kiosco.

Inicié labores en el mes de abril de1981, los estudiantes asistían a clases en horario de 8:00 a.m. a 4:30 p.m., con receso para almorzar. Un kiosco constituía el aula de clase, en temporada de lluvia 
resultaba imposible trabajar en ese espacio, el agua entraba por todas partes, ante esa situación motivé a la comunidad para restaurarlo durante el receso escolar de medio año. Al año siguiente se organizaron bazares para conseguir dineros y construir un nuevo salón, mejorando así las condiciones de estos estudiantes y las posibilidades para desarrollar la labor educativa. A finales de 1981, para cobrar el salario de noviembre era necesario recitar estrofas del Himno Nacional, donde el director de Núcleo decidía cuál estrofa preguntar.

A mediados de 1982, me presenté al concurso docente para ingresar al Distrito Capital, lo aprobé, pero la comunidad no aceptaba que dejara la escuela, por tanto, no pude sacar mis cosas personales, dado que intentar hacerlo me creaba graves problemas, le avisé sólo a mis compañeras y al Director de Núcleo.

En 1983 inicié labores en Bogotá, las condiciones laborales eran difíciles, la escuela ubicada al suroriente de Bogotá pertenecía al sector rural, el transporte me dejaba lejos del sitio de trabajo, en temporada de lluvia el acceso resultaba difícil. Las familias afrontaban necesidades económicas pero se interesaban por sus hijos. El equipo de trabajo era maravilloso, la solidaridad se vivenciaba en todo momento, tanto hacia las familias como hacia los compañeros docentes. Asistíamos a velorios en el barrio, visitábamos a las familias para darles voz de aliento ante diversas necesidades. Por tanto, nuestra labor docente reconocía siempre las características del contexto y nos exigía una actitud más participativa, las relaciones con la comunidad fueron determinantes en el éxito de nuestro quehacer.

El acceso a la ciudad estaba permeado por el deseo de continuar estudios superiores, ingresé a estudiar la Licenciatura en Ciencias Sociales en la Universidad Pedagógica Nacional, compartir la práctica pedagógica con la formación académica en la universidad fue significativo, al permitirme confrontar los saberes de la licenciatura con nuevas experiencias como docente.

La Secretaría de Educación ofrecía a los docentes la posibilidad de asistir a cursos para familiarizarse con estrategias didácticas de trabajo, con el apoyo de la Dirección de Investigación para la Educación -DIEy del Centro Experimental Piloto -CEP- del Distrito Especial de Bogotá, posibilitando así ascender el Escalafón Docente.

La jornada laboral me permitió adelantar mis estudios universitarios de pregrado. Posteriormente las expectativas se ampliaban, ingresé a la Universidad de la Sabana para realizar estudios de posgrado, ampliando las posibilidades de desempeño laboral, ingresé a la docencia universitaria.

En la Facultad de educación de Uniminuto me brindan la posibilidad de vincularme con algunas cátedras. Con gran responsabilidad asumo el rol profesional acorde con las políticas institucionales. Repensar los elementos temáticos de las asignaturas hacía parte de la cotidianidad, el encuentro permanente con docentes dinamizaba el compromiso y el sentido de pertenencia. Esta mirada retrospectiva

REPENSAR LOS ELEMENTOS TEMÁTICOS DE LAS ASIGNATURAS HACÍA PARTE DE LA COTIDIANIDAD, EL ENCUENTRO PERMANENTE CON DOCENTES DINAMIZABA EL COMPROMISO Y EL SENTIDO DE PERTENENCIA. 
permite tener una visión valorativa del crecimiento y la cualificación permanente del ambiente universitario.

La práctica pedagógica procura generar actitudes de cambio tanto en el sujeto como en los contextos de interacción, en tal sentido involucra reflexionar frente a la escuela, al currículo, a las políticas educativas, a las didácticas, de tal manera que desde el accionar se genere impacto para transformar las comunidades.

Uniminuto, al preferenciar la praxeología en su proceso pedagógico, convoca la atención de los docentes para fomentar procesos autónomos, actitudes reflexivas, donde él no es un actor desprevenido, por el contrario es un sujeto que investiga y genera actitudes investigativas con sus estudiantes, creando ambientes de aprendizaje motivantes que favorecen la formación profesional de los futuros licenciados.

La praxeología exige al docente un continuo cambio de mentalidad, de prácticas y costumbres pedagógicas y así mismo estar muy cerca de la realidad e intereses de los estudiantes, como también una reafirmación y retroalimentación de los conocimientos en su saber específico para orientar un proceso de construcción personal y colectiva que integre teoría y práctica, y que implique la conformación de comunidades académicas e investigativas de alto impacto social.

El encuentro con los estudiantes permite repensar la implementación de metodologías que posibiliten la participación activa y decidida del grupo, cualificando su propia formación, para potencializar la toma de decisiones ante una gama amplia de posibilidades, en tal sentido el desarrollo de la autonomía se acrecienta y afianza, hecho que permite el cuestionamiento y la búsqueda tanto de sentido como de explicaciones para la comprensión como para la resolución de situaciones problemáticas, donde el docente se presenta como orientador de procesos.

La investigación formativa es un reto frente a la reflexión permanente, permite una mirada retrospectiva y prospectiva de la práctica. Desde los primeros semestres, los estudiantes requieren de acompañamiento y asesoría, espacios que se evidencian en el desarrollo de las Tutorías ofrecidas por la Facultad de Educación para los diferentes semestres y que le permiten al estudiante articular saberes e implementarlos en su cotidianidad.

La socialización de experiencias le permite a los docentes en formación confrontar su práctica pedagógica, sus saberes, establecer semejanzas y diferencias, valorar sus desempeños, establecer relaciones entre teoría y práctica, para hacer juicios de valor y establecer acciones concretas que den respuesta a las necesidades detectadas. Por tanto el aula y la práctica pedagógica se presentan para los estudiantes como espacios para generar confianza en sus capacidades, de tal manera que contribuyan a cualificar su labor docente.

La universidad, desde su sentido prospectivo, se preocupa por ofrecer educación integral que implica formar personas con proyección social, con alto sentido de pertenencia y compromiso que desde el sujeto tenga proyección hacia el otro, por tanto el docente debe ser un sujeto trascendente. 
En tal sentido, la planeación de la clase debe estar sustentada en criterios de flexibilidad, de tal manera que permita realizar ajustes ante las necesidades, particularidades e intereses del grupo de estudiantes. Los acuerdos alcanzados, junto con las directrices institucionales, se convierten en estrategias que armonizan el quehacer académico y generar compromisos para la vida personal y profesional.

La práctica pedagógica debe estar sujeta a revisión permanente de tal manera que permita evaluar su impacto en los diferentes actores involucrados y realimenta el proceso. Un proceso que no se revise corre el riesgo de caer en la rutina al no valorar su funcionalidad y pertinencia.

La evaluación permite al sujeto actuar con sentido crítico, tanto en su vida personal como profesional, con el ánimo de aportar espacios reflexivos a las comunidades y estrategias de mejoramiento.

La experiencia laboral en UNIMINUTO ha sido gratificante, al permitirme compartir su crecimiento tanto desde los espacios físicos como en el campo académico. Vale recordar algunos aspectos sobresalientes en la evolución de la universidad, pasando de unas facultades con pocos estudian- tes en la pasada década, a una universidad con programas acreditados por su calidad académica, los convenios institucionales con universidades nacionales e internacionales que contribuyen al reconocimiento de la universidad en el contexto nacional e internacional.

El camino recorrido en la Universidad desde mi vinculación con la Facultad de Educación, como docente catedrático, Coordinador de práctica profesional, Coordinador de la Licenciatura en Educación Básica con Énfasis en Educación Religiosa, me ha permitido evidenciar con gran complacencia y admiración el sentido de proyección institucional atendiendo a los retos de calidad y competitividad, donde la valoración por la persona gana reconocimiento permanente. La Universidad ha contribuido en mi cualificación profesional mediante la participación en eventos académicos y la consolidación de un proyecto de vida que articula lo personal con lo profesional.

La constante preocupación por mantener un cuerpo directivo y docente cualificado, con alto sentido de pertenencia institucional y proyección social han posicionado a la institución en un alto estatus, donde todos los que colaboramos desde distintas instancias nos sentimos orgullosos de pertenecer a Uniminuto. 


\title{
2. LA HISTORIA DE VIDA COMO UNA FORMA DE COMPRENDER LA DOCENCIA
}

\author{
Por: Francisco Perea MOSQUera ${ }^{6}$
}

\section{Introducción}

$\mathrm{A}$ l escribir esta historia de vida, se pretende elaborar una reflexión en torno a los procesos de formación de docentes y las huellas que dejan aquellos que de una u otra forman generan inquietudes y motivaciones, que en muchas circunstancias, desde el ejemplo, hacen posible que algunas personas desde sus niñez se inclinen por una labor digna de construcción colectiva y de aportar lo mejor de sí para que otros seres humanos se formen y construyan sus propios senderos.

Esta reflexión se desarrollará desde la Praxeología Pedagógica, la que de acuerdo con los planteamientos del padre Carlos Juliao ${ }^{7}$, permite la reflexión reconstructiva de las vivencias y la práxis en general. Esta propuesta se sustenta en cuatro fases: VER, JUZGAR, ACTUAR Y DEVOLUCIÓN CREATIVA.

Esta historia de vida se construirá desde el proceso praxeológico. Se han definido algunos criterios desde los cuales se elaborará este escrito: en el VER se tienen en cuenta las influencias de la familia, la escuela primaria, la Escuela Normal Superior, la formación universitaria de pregrado y postgrado. Es esta fase, en lo que tiene que ver con las instituciones formadoras, se hará referencia a aquellos maestros y personas del contexto social que de una u otra forma aportaron en lo que Francisco Perea es hoy como docente.

En el JUZGAR se hará la interpretación de de los hechos del ver. En el ACTUAR se hará alusión a todos aquellas situaciones de la praxis que hicieron posible mi actuación como docente. En este sentido se tiene mi nombramiento como maestro en Suruco de Santa Mónica en el Departamento del Chocó, el Colegio Nacional Andrés Bello del Barrio Muzú de Bogotá. Por otra parte, la experiencia en las universidades
Pedagógica Nacional y la Corporación Universitaria Minuto de Dios, al igual que la experiencia como asesor externo en el Convenio Andrés Bello en formación de docentes en investigación y pedagogía.

En la DEVOLUCIÓN CREATIVA se tendrá en cuenta lo aprendido de los padres, de los amigos, de los colegas, mis hermanos e hijos.

\section{El ver como una forma de aprender de los ejemplos}

Francisco Perea Mosquera es hijo de Digno Antonio Perea Murillo y Rosa Mosquera Asprilla. Los padres de Digno fueron Froylan Perea, quien era comerciante, y Primitiva Murillo, ama de casa. Los padres de Rosa fueron Pedro Pablo Mosquera, quien asistió a la escuela y su formación la logró en forma autodidacta. Era un hombre de 2:00 metros de estatura y muy paciente, por sus méritos llegó a ser concejal del municipio de Istima en el Departamento del Chocó, siendo un hombre connotado en este municipio. Era una persona que dialogaba mucho con los nietos y además nos contaba sobre su vida.

Alguna vez le pregunté cómo había sido la educación recibida y me contó que su familia vivió en un pueblito a tres kilómetros de Istmina, denominado San Pablo Adentro y el sustento lo derivaban de la minería, y que generalmente todos los fines de semana iban a Istmina a hacer el mercado para la semana, después de vender el oro que habían logrado obtener como resultado de su trabajo en la mina. Estos no sabían leer ni escribir y mucho menos las operaciones matemáticas, por lo que el Señor Antonio Asprilla, gran negociante, dueño de un almacén era a quien le vendían el oro, le compraban el mercado y les hacía las cuentas, las 
que para mis bisabuelos maternos siempre estaban bien hechas.

Cuando Pedro Pablo creció, sus padres le encargaron la tarea que ellos realizaban, es decir, vender el oro y comprar el mercado. Cierto día mi abuelo le dijo a "Don Antonio"que si le podía enseñar a contar, a lo que éste accedió, pero con la condición que sería a ratitos, los sábados cuando fuera a hacer el Mercado.

Así trascurrió el tiempo, hasta que uno de esos sábados Pedro Pablo, como de costumbre, hizo el mercado y cuando regresó a San Pablo Adentro donde sus padres, les mostró las cuentas y las vueltas, después de haber hecho el mercado, por lo que sus padres lo regañaron y le dijeron que de dónde había el sacado esa cuentas, que él "no podía haber aprendido eso porque a los negros no se les estaba permitido estudiar", es de aclarar que Antonio Asprilla era mestizo, razón por la cual había podido acceder a la educación. Él les contó que don Antonio Asprilla le había enseñado, entonces acordaron que al sábado siguiente irían a confirmar lo dicho por mi abuelo, lo que fue confirmado por este señor. En lo sucesivo fue mi abuelo el encargado, no sólo de hacer las cuentas a sus padres, sino a muchas personas de San Pablo Adentro. En honor a quien le enseñó los primeros números y lo apoyó para que aprendiera a leer, mi abuelo bautizó a su hijo menor con el nombre de Daniel Antonio, quien se acaba de pensionar de maestro en Istmina en la escuela donde yo Nací.

Este asunto no termina con aprender las operaciones matemáticas básicas, Pedro Pablo sintió la necesidad de aprender a leer y a escribir, entonces don Antonio Asprilla le regaló un texto, que era "la Biblia en la lectura". Esta cartilla se denominaba la Citolegia y me contaba que por sus propios medios aprendió a leer y a escribir, decía que en este prodigioso libro, cuando a partir del desarrollo de los ejercicios se llegaba a la palabra reloj, ya se sabía leer. Este libro llevo buscándolo desde que tenía la edad de 12 años, es decir, hace 39 años, que fue la edad en que mi abuelo Pedro Pablo me contó esta historia. Si algún lector lo ubica por favor hágamelo saber. Los ejercicios de escritura los hacía en una pizarra pequeña, lo que reemplazaba el cuaderno, con la diferencia que se escribía con roca caliza, la que hacía las veces de tiza, y tocaba borrar lo escrito, lo que exigía una excelente memoria. Desde que mi abuelo aprendió a leer ningún día dejó de leer hasta su muerte, además tuvo una excelente visión, pues nunca necesitó anteojos.

Mi abuela materna tenía por nombre Sixta Asprilla, me contaba mi madre, que era de un temperamento recio. La madre de mi abuela era indígena, la llamaban "la chola Dominga, murió a los 105 años, y su padre era afrodescendiente".

Mi nacimiento ocurre dos días después de la muerte de mi abuela materna. Mi familia vivía en Andagoya, en esa época corregimiento del municipio de Istmina, donde trabajaba mi padre en la planta eléctrica, perteneciente a una empresa norteamericana denominada “Compañía Minera Chocó Pacífico". Mis padres se habían desplazado a Istmina a las Honras fúnebres de mi abuela Sixta y en pleno duelo, mi madre sintió los dolores del parto a las 20 horas del día 25 de abril de 1956. En ese momento la llevan al hospital en una camilla y a pie, precisamente cuando iban, perdón, íbamos al frente de la Escuela Policarpo Salabarrieta ocurre mi nacimiento, es decir, nací al frente de una escuela por lo tanto desde mi nacimiento nací afortunado y con la insignia para ser maestro porque la escuela y la docencia me escogieron para esa noble misión.

\section{La vida en Andagoya}

En Andagoya trascurrió mi infancia, nunca asistí al preescolar porque en esa época no se usaba. Mi padre estaba suscrito a El tiempo y allá, al interior de la selva, llegaba el periódico cada dos días, en una avioneta de 
la compañía en la que él trabajaba, el periódico era distribuido por un señor de apodo Kiko, quien era el agente de esta editorial. Mi padre nos leía el periódico todos los días, de esta forma se nos estimuló la lectura y el interés por conocer lo que pasaba, no sólo en el país, sino en el mundo.

A la edad de 6 años mis padres hablaron al director de la Escuela Pascual de Andagoya, institución Educativa de carácter privado donde solamente estudiaban los hijos de los empleados de la Compañía Minera Chocó Pacífico. En esta escuela todos los útiles escolares eran proporcionados en forma gratuita a todos los estudiantes. Existía una excelente biblioteca de la que los estudiantes podían sacar libros prestados para llevarlos a la casa. Fue allí donde conocí la serie del tesoro de la juventud donde había una adivinanza que decía: "El rey Alí y su perro can se fueron a tomar el té a la ciudad que le he dicho a usted" y la respuesta era Alicante. Hace tres años logré conseguir 7 tomos de esta enciclopedia a mis hijos y todavía disfrutar al leerla.

Cuando mis padres hablaron con el director, el profesor Eleicester Murillo, él les dijo que no me podía aceptar en la escuela porque solamente tenía seis años y la edad de ingreso era siete, mis padres le insistieron que me aceptara como asistente a lo que éste accedió. Al finalizar el año, con mucho apoyo de mis padres, aprobé el curso primero, pero como no tenía la edad me hicieron repetir este grado porque era muy pequeño, según las normas de ese momento. Mi profesora en este curso se llamaba Epifanía, una mujer alta y fornida pero muy tierna y cariñosa, fue la que me enseñó las primeras letras. Una mujer de una excelente paciencia, creo que por eso era la maestra del curso más difícil, primero.
El horario escolar era el mismo que se utilizaba en la empresa donde trabajaba mi padre, es decir, el horario utilizado en Estados Unidos; a las 6:00 de la mañana sonaba un pito, muy parecido al que utilizan los buques de gran calado, se escuchaba en todo el pueblo de Andagoya, era para organizarse, a las 6:30 todo el mundo debía estar listo, a las 6:45 se estaba en el sitio de trabajo o la escuela y a las 7:00 se iniciaban las labores. A las 11:30 sonaba el pito se salía a almorzar, a las 12:30 sonaba para salir al trabajo y a las 13:00 se iniciaban de nuevo las labores, para terminar a las 16:00. Existía también una sirena que solamente sonaba en casos de emergencia, estos dos quedaban en la planta eléctrica donde trabajaba mi padre. En ocasiones, el 31 de diciembre cuando mi padre estaba en turno nocturno tuve la fortuna de hacer sonar el pito de año nuevo.

A la salida de la escuela se hacía filas por barrio, yo pertenecía al barrio El Porvenir, también apodado Corea. Cada fila estaba conformada por estudiantes de diferentes cursos, el único dicterio era el de vivir en el barrio al que pertenecía la fila. En cada una de éstas había un monitor. Los monitores eran los estudiantes que vivían en las últimas casas del barrio, por tanto siempre eran los hermanos Mosquera, Arnulfo (Curtis ${ }^{8}$ ), Ricardo (Richie) y Romelio, quienes además eran fuertes para pelear y no eludían pleito. Esta característica les servía debido a que se les formaban muchas broncas por su condición de monitores. Esta monitoría era heredada por los hermanos menores.

Los monitores reportaban tanto en las mañanas como en las tardes a los que hacían indisciplina, bien por que se salieran de la fila antes de llegar a 
sus casas o porque generaran alborotos o peleas, sólo se hacía filas al salir de la escuela. Se recorría todo el barrio en fila, los monitores iban por fuera de esta, anotando en un cuaderno a todos aquellos que se portaban mal y entregaban la lista a los profesores encargados de la disciplina en ese día. Los estudiantes que aparecían en la lista eran castigados físicamente o haciendo aseo en la escuela.

El aseo y organización de los salones y baños estaba a cargo de los estudiantes, en cada curso se hacía una lista semanal y en las tardes a los que les correspondía el aseo se quedaban en compañía del profesor del curso hasta que terminaran.

En esta escuela se hacían concursos de ortografía y de cálculos matemáticos. El uniforme era bluejean, los que generalmente eran marca el Toro y Zefair, y los zapatos negros de marca Grulla o Hechego. Había estudiantes que llevaban charangas, zapatos de plástico, los que se calentaban mucho y generaban malos olores.

En mi paso por la primaria mis profesores inculcaban el respeto, la ética, estética y el deporte. Todos los viernes en la mañana se hacía jornada deportiva, donde cada estudiante podía practicar los deportes de pelotas que quisiera y había un maestro que hacia las orientaciones respectivas. En la tarde del viernes se hacían actividades culturales, donde los y las estudiantes participaban de acuerdo con sus actitudes artísticas. Es importante precisar que la unidad en escolar había niños y niñas y era hasta quinto de primaria, pero las niñas tenían sus aulas a parte, el encuentro mixto era en los descansos, puesto que éstos coincidían. Existía una directora para las niñas y un director para los niños, estos cargos eran casi vitalicios.

\section{La vida en la normal superior}

Al terminar quinto de primaria, por la influencia de mis maestros Eleicester Murillo y Absalón
Mosquera, quienes eran egresados de la Normal Superior de Varones de Quibdó, opté por estudiar para maestro. Estos dos profesores frecuentemente entonaban el himno de su Normal y sobretodo un estribillo que dice: "Viva por siempre la normal madre de los educadores, también que vivan eternamente los estudiantes $y$ profesores...." lo que denotaba su identidad con esta institución y con la profesión. Creo que ello incidió mucho en mi elección, al salir de la primaria le expresé a mis padres que quería ser maestro, pero como en Andagoya ni en ningún municipio cercano había Escuela Normal, entonces mis padres, sobretodo mi madre, decidieron que lo mejor era estudiar en Quibdó.

En el mes de noviembre de 1969 mi madre viaja a la capital de Chocó y me inscribe en la Normal superior para Varones de Quibdó, con el fin de concursar para un cupo. El día 20 de Enero de 1970 me presentó al examen, al que nos presentamos 120 aspirantes, de todos los confines del departamento. Este examen lo presentamos en el aula múltiple, yo no conocía a nadie y además como estudiante de provincia y era la primera vez que iba a la capital, la timidez me superaba y ni antes ni durante el examen crucé palabra alguna con alguien.

Al salir del examen de admisión, se me acercó otro de los examinados y entabló conversación conmigo, esa persona se llama Víctor Dueñas, a partir de allí se convirtió en mi mejor amigo y estuvimos durante todos los años en el mismo curso, hasta graduarnos de maestros. Cierto día hicimos un pacto, consistente en que cuando fuésemos adultos y tuviéramos nuestros hijos cada uno sería el padrino de los hijos del otro. Pacto que hasta la fecha se ha cumplido. Víctor, apodado Vitucho, es el padrino de mis tres hijos y yo, de los cuatro de él.

Debido a la amistad entre Vitucho y yo, nuestras madres se convirtieron también en excelentes amigas y la una visitaba a la otra, donde estuviera, viajaban de paseo 
juntas y se llegaron a entender muy bien hasta la muerte de mi madre.

En el grado primero de la normal, al culminar el año, fui condecorado con matricula de honor y una beca, consistente en $\$ 100.00$ mensuales, honores que disfrute hasta graduarme. El haber vivido en Andagoya, un contexto intercultural y por ser un medio donde se hablaba mucho inglés y además mi padre lo entendía medianamente, por los contactos en la empresa y además su jefe Mr. Schuller, era norteamericano y hablaba muy poco el español.

También incidió el cercamiento al inglés, el tener primos dado que su abuelo era jamaiquino y éste hablaba casi todo el tiempo en inglés o mezclándolo con el español y cuando íbamos de visita se escuchaba hablar este idioma, también algunos compañeros de curso en la Escuela Pascual de Andagoya eran bilingües, como es el caso de Walter Almendinger, hijo de chocoana con Suizo y Barry Rum, hijo de norteamericano y chocoana.

En mi paso por la Normal recibí una excelente formación en todas las áreas. Me acuerdo que las clases de Educación Física, a cargo del profesor Efraín Córdoba, eran muy exigentes y estaban basadas en la gimnasia, el atletismo, sobre todo en pruebas de resistencia. Era una educación física de tipo militar. Creo que ello y la formación deportiva recibida en la primaria, incidió para que hiciera parte de la selección de Baloncesto de la Normal y posteriormente optar por el atletismo, en las pruebas de lanzamiento de bala, disco y jabalina, llegando a representara al Chocó en eventos nacionales. El deporte se me convirtió en un gran bastión para el fortalecimiento de la disciplina y el rigor.

En la normal disfrutaba todas las clases, sobre todo las de Ciencias, Matemáticas y Pedagogía. En esta última destaco las del profesor Conrado Moreno, quien vestía de corbatín y calzonarias. Enseñaba pedagogía desde la relación entre las teorías pedagógicas del momento y las vivencias, nunca lo vi en las clases sacar algún cuaderno o libro para orientar la clase, tampoco enseñaba memorísticamente, fortalecía la comprensión. Contaba chistes pero no nos podíamos reír mucho tiempo, tan pronto el chiste terminaba se ponía serio e hilaba el tema a lo chistes.

Otro excelente profesor a destacar fue Héctor Moya, quien era muy exigente, pero enseñaba muy bien las ciencias naturales y se hacían muchas prácticas de laboratorio. En las clases de química asociaba los nombres de los compuestos con los de personas o situaciones, por ejemplo, para el TNT o Trinitotolueno, que es un explosivo, le denominaba Tomás No Toma y con eso nos acordábamos del compuesto, al Dicloro Difenil Tricloroetano o DDT le denominaba Déjeme Dormir Tranquilo y así sucesivamente. Creo que ello incidió en mi elección por la Licenciatura en Química y Biología.

\section{El juzgar como postura en la formación}

El haber nacido en una familia que desde mis abuelos, específicamente Pedro Pablo y mis padres haber tenido Interés por el conocimiento, fue un caldo de cultivo para que yo optara por la profesión de maestro. También influyeron mucho mis maestros de la primaria al igual que algunos de la Normal. Mis padres fueron maestros incansables en la formación de sus hijos. Por el lado de los tíos maternos un incansable esfuerzo de superación, pues mi abuelo se esforzó porque sus hijos lograran estudiar, de allí que haya dos ya pensionados en la docencia y todos han sido muy correctos y humanistas.

Mis padres eran personas muy dedicadas a la amistad y desprendidos de las cosas materiales, de buen genio, le hacían chiste a todo y permanentemente estaban formulando preguntas, de igual modo inspiraban confianza y con ellos se podía hablar de cualquier tema por escabroso que fuera. A los hijos nos inculcaron la unidad y la solidaridad, inclusive cuando algún hermano peleaba con otra 
persona había que estar allí para apoyar. Si dos hermanos peleaban, mi madre los hacía abrazar arrodillados hasta cierto tiempo y después debían pedirse perdón mutuo.

Mi hermano Wilfrido, mayor que yo en dos años, me enseñó la disciplina de la selva, desde cómo cortar leña, cómo diferenciar las plantas que en la selva eran de consumo humano y las tóxicas. De igual forma, cómo utilizar el machete para cortar el monte en la selva y el hacha para los árboles que servían para cocinar, también la forma de defenderse de los perros, por ejemplo, me decía que a un perro cuando es bravo y te ladra no se le debía dar la espalda, había que mirarlo de frente a los ojos que ello lo hacía acobardar y huir, porque generalmente los perros bravos muerden por la espalda y en las piernas.

De todo lo anterior creo que es importante valorar la amistad, en ella se centra la capacidad humana de tolerar y de solidaridad, como reza una frase chocoana, el que es buen hijo, es buen hermano, buen amigo, buen padre y buen esposo. Expresiones que recogen la esencia relacional del ser humano, lo que implica la importancia que deben tener los padres para los hijos, lo que debe estar basado en el respeto. Lo anterior implica que el que es mal hijo no puede tener buenas relaciones con nadie. Estas expresiones derivan de la cultura chocoana de la que soy hijo.

La formación docente no debe ser concebida únicamente desde lo institucional, desde los planteles educativos, sino el resultado de múltiples factores, inclusive los ancestrales, donde los abuelos padres, hermanos, amigos, vecinos y ancianos de la comunidad han aportado en mi estructuración como sujeto de la educación. Por ejemplo, en mi barrio, en Andagoya, hubo un señor que cursó hasta quinto de primaria, al igual que mi padre, se llamaba Arnobio Lozano. Este señor tenía gran dominio de la palabra y en las noches desde su casa de madera color verde y gris, salía al balcón a las 7 de la noche y contaba cuentos para todos los vecinos, quienes también salían a sus balcones a escuchar. Esta cita era generalmente los días lunes miércoles y viernes. Todos los niños y adultos, sin ningún aviso previo, salíamos a los balcones. La única condición para contar los cuentos era que nadie interrumpiera sus intervenciones, de lo contrario nos castigaba dejando de contar cuentos la sesión siguiente. Esto obligaba a todo el mundo a permanecer atento.

En otras oportunidades, el vecino Arnobio recitaba décimas, unas composiciones que podían durar horas. Este señor tenía una excelente memoria, nunca lo vi sacar apuntes para guiarse en las narraciones. Había noches en que los cuentos eran del compadre rico y el compadre pobre, otras de las pilatunas que le hacía el tío conejo al tío tigre, en otras sesiones contaba cuentos de terror, lo que generaba pánico en los niños. Estas expresiones narrativas de alguna forma han incidido en mi orientación por la tradición oral, reconozco que me es más fácil narrar que escribir, porque somos hijos de lo que recibimos y en nuestra cultura chocoana la tradición oral es "el pan de cada día”.

La escuela primaria y mis vivencias infantiles y los aportes educativos de la familia, reforzaron en gran medida la interculturalidad y el no considerarse inferior a nadie por ninguna condición, por ejemplo, en el pueblo donde viví mi infancia por la empresa minera extranjera que existía allí, había personas de todas partes del mundo, llegaba información de todas partes. Muchos términos del español vine a conocerlos cuando fui a estudiar a la normal en Quibdó.

Además de la formación pedagógica, en la normal de Quibdó aprendí a reconocer que no todos los pueblos del Chocó eran como Andagoya -lugar donde viví mi infancia-, también aprendí que el transporte en lancha o en carro había que pagarlo, porque en Andagoya era gratis, aprendí que los útiles escolares y libros había que comprarlos. 
En la normal tuve un profesor de prácticas agropecuarias, Jesús Perea, joven quien más que profesor, era nuestro amigo, compartía con nosotros los partidos de fútbol. Este profesor organizó una excursión a la Salada Antioquia a una sede del SENA, con el fin de hacer unas prácticas, pero la intención era la que muchos conociéramos lo que realmente era una ciudad. Algunos nunca habíamos visto un semáforo real ni calles tan anchas. Fue una experiencia grandiosa.

\section{El actuar como simbiosis del ver y el juzgar}

El día 27 de agosto de 1977 fui nombrado como maestro de Suruco de Santa Mónica, corregimiento del Municipio de Istmina, siendo el inspector de policía, Justino Hurtado.

Mi primera experiencia como maestro fue muy interesante, me acuerdo que me había graduado el 30 de Noviembre de 1975 y sólo fui nombrado como maestro casi dos años después. Debía presentarme lo más pronto posible al sitio de trabajo porque los estudiantes estaban sin maestro desde hacía cuatro meses, entonces mi madre se dio a la tarea de averiguar con conocidos suyos donde quedaba ese corregimiento y quien nos podía guiar hasta allá. Logró contactar a un señor de nombre Luís Arturo, un hombre alto de por lo menos dos metros de estatura, que calzaba más o menos 48 y no usaba zapatos, además tenia el ojo izquierdo con estrabismo, como decimos en el Chocó, "era virolo".

Mi madre le dijo a Luís Arturo que nos guiara hasta Suruco de Santa Mónica el día 1 de Septiembre, pues era necesario iniciar ese mismo día pues era lunes y además primer día del mes. Este pueblo quedaba a tres horas de camino y había que cruzar ríos y quebradas, además había que contar con la suerte que no estuviera crecido el río San Pable, el más caudaloso de esa región, de lo contrario nos tendríamos que devolver, pues no había puentes y la única forma era caminado cuando estaba pandito o nadando.
En la cima de una montaña había un sitio denominado el Tambo, donde existió en los tiempos de la esclavitud, una bodega donde las cargas que venían desde Cartagena se depositaban allí. A través del Istmo de San Pablo se traía esta mercancía, puesto que no existía la carretera Istmina-Quibdó.

Caminamos todo un día y no conseguimos el pueblito, pues Luís Arturo, el guía, se había perdido y no encontramos el verdadero camino. Nos dijo que el duende lo había hecho perder y que al día siguiente lo intentaríamos de nuevo.

Pero la sabiduría de Ma Rosa, como le decían muchas personas a mi madre en el Chocó por su condición de matrona, hizo nuevos contactos y le informaron que el día sábado, al igual que ocurría cuando mi abuelo Pedro Pablo vivía con sus padres en San Pablo Adentro, los habitantes de Suruco salían a Istmina a comprar "sus víveres", es decir, el mercado.

De esta forma le dijeron que había una persona que nos podía guiar. Este personaje se llamaba Jorge Quinto Waldo, un hombre bajito de 1,60 metros de estatura, un gran conocedor de la selva por la que teníamos que transitar. Este personaje era "tartajoso", lo que me obligaba a prestar mucha atención a lo que decía o a pedirle el favor de repetirme.

Llevábamos una semana perdida y el día lunes de la siguiente, después de la confusión con el primer guía, salimos a las seis de la mañana. Compré un mercado para la semana, llevaba unas botas de caucho marca La Macha, un machete al cinto, un morral, un sombrero de paja y una oración de la virgen del Carmen, que me había regalado mi madre para que la rezara todas las noches y en las mañanas para que me protegiera de todo mal y peligro. Esta vez mi madre no fue.

En esos momentos yo ya era atleta y creía que ello me habilitaba para desplazarme con "vaquía"10, 
pero una cosa es trotar en una pista atlética o en las playas o en las calles y otra caminar rápido en la selva, donde hay que saltar troncos, pasar puentes de un solo madero. Tengo que confesar que Jorge me volvió trizas y tenía que decirle que me esperara en el camino.

Este recorrido se hacía en una selva espesa, donde había lugares en los que los rayos del sol se filtraban muy poco entre los árboles gigantescos de Caimito, Azulito, Chachajo, Sangre de Gallo, Algodoncillos, Cedro, Guamo Cajeto, Yarumos, madera que no se podía utilizar en los fogones porque no ardía ${ }^{11}$; Guayacán negro, este último una especie de madera que cuando se humedecía era más fuerte que estando seco y para poderlo utilizar en la construcción de viviendas los carpinteros o constructores de casas tenían que perforarlos con taladros de rosca fina porque era imposible la utilización de puntillas cualquiera que fuese su dimensión. Los nombres de estos árboles y su diferenciación en la selva, me los enseñó mi hermano Wilfrido, quien conocía la selva como "las palmas de sus manos".

Ese día llegamos a Suruco de Santa Mónica a las 10:00 de la mañana y los y las estudiantes me estaban esperando porque ya les habían avisado que iba un nuevo maestro. En el pueblito solamente estaban los niños porque los padres unos estaban en las fincas y otros en las mina, entonces me reuní con estos y les dije que mientras yo me organizaba, nos veríamos en la escuela a las 2:00 de la tarde. La escuela era un salón donde cabían 20 personas, una habitación donde vivía el maestro y una cocina. En la escuela no había baño ni ducha. Existía una letrina comunal y para bañarse había que hacerlo en el Río Suruco, un río de aguas cristalinas, muy fría.

Ese día a las dos de la tarde, como lo habíamos acordado, nos reunimos con los estudiantes, nos presentamos y les conté algunos cuentos de los que mi vecino Arnobio contaba en Andagoya cuando yo era niño y les fascinó. De allí en lo adelante me comprometí a contarles cuentos, como mínimo uno semanal, lo que me obligó a inventarlos puesto el repertorio que había aprendido de niño se me agotó rápidamente.

Esta tarde les pregunté a los estudiantes en qué curso estaban y, cual fue la sorpresa que los 16 niños y niñas pertenecían a cursos muy distintos, estaban entre primero y tercer grado. En la normal me habían enseñado qué hacer, pero una cosa es la teoría y otra cuando nos enfrentamos a la realidad. Entonces hubo que hacer uso de lo que había aprendido en la normal sobre la Escuela Nueva.

De allí en adelante se trabaja con unas guías que existían en la escuela para esos cursos, de tal forma que cuando estaba explicándole a los de primero, los estudiantes de los otros cursos estaban trabajando sus guías.

Ese primer día al finalizar la jornada me reuní con los padres de familia y me les presenté al igual que al inspector, quien me firmó el acta de presentación al trabajo. Al inspector de policía le correspondía todos los meses firmar la constancia de que el maestro había asistido todo el mes al trabajo, de lo contrario no le

MIS PROCESOS PRAXEOLÓGICOS VIENEN DE LA SELVA CHOCOANA, PARA POSICIONARSE EN LAS GRANDES URBES COMO BOGOTÁ, LO QUE NO HA SIDO FÁCIL Y DE LO QUE ME SIENTO ORGULLOSO. 
pagaban y si faltaba algún día sin justificación se le descontaba del salario. Los permisos laborales debían ser pedidos al inspector de policía como representante de la Secretaría de Educación y de la autoridad departamental.

Al terminar esa semana de trabajo, Jorge me acompañó de nuevo, se quedó en mi casa y así estuvo acompañándome los lunes al ingresar al trabajo y los viernes a mi regreso a Istmina. Es necesario aclarar que después de graduarme como maestro nos trasladamos a vivir a Istmina, segunda ciudad del Departamento del Chocó.

Cuando ya consideré que conocía bien el camino de Istmina a Suruco de Santa Mónica, resolví agradecer al guía su compañía, quien no me cobraba ni un centavo. Cierto día traté de pagarle y se me enojó diciéndome que lo hacía con el mejor gusto y que en ese pueblo el maestro representaba mucho para ellos, luego quienes deberían estar agradecidos eran ellos y que estaban en deuda conmigo por contribuir en la formación de sus hijos. Jorge accedió a esta petición y de allí en adelante transité solo, cada semana, esas tres horas de camino.

Este trabajo lo combiné con el estudio en la Universidad Tecnológica del Chocó, cuando decidí, por la influencia del profesor Héctor Moya de la Normal Superior para Varones, estudiar Licenciatura en Química y Biología. Licenciatura que era en la modalidad a distancia, puesto que esta universidad hizo un convenio con la alcaldía consistente el proporcionar un colegio para que allí se hicieran las clases y los otros municipios de la región, entre ellos Condoto y Tadó los aportaban algunos recursos económicos para cubrir parte del sostenimiento de este proyecto.

Fue así como logré estudiar mi licenciatura, los viernes, sábados y domingos. Los viernes las clases eran de 3 a 10 p.m. y los sábados 7 a.m. a 12 m, y de 2 a 10 p.m. y los domingos de 7 a.m. a 1 p.m. Este proceso duró cuatro años y medio.
Tan pronto terminé la carrera, inicié a estudiar la licenciatura en idiomas, con el único fin de aprender inglés y francés, en el sexto semestre me retiré, pues mi intención no era la de ser licenciado en esta área, sino la de continuar formándome en Ciencias Naturales.

Esta formación fue complementada con el acceso a la Maestría en Docencia de la Química en la Universidad Pedagógica Nacional, en la que a partir de un examen de admisión y entrevista, logré salir adelante y ganarme una beca, consistente en la exoneración de matrícula y el reconocimiento de un salario, que para esa época era bueno. Esta maestría fue de carácter presencial, todos los días.

Posteriormente me vinculo como docente en el Instituto Alberto Merani, creo que este espacio ha sido una de mis mejores escuelas en la formación académica, al mismo tiempo como catedrático en el Colegio Andrés Bello del Barrio Muzú, posteriormente en la Universidad Pedagógica, la que me ha fortalecido y mostrado otros horizontes pedagógicos, escuela que a nivel nacional hace aportes trascendentes en cuanto a educación se refiere, para luego incursionar en la Corporación Universitaria Minuto de Dios, donde la praxeología y lo social han hecho de mi un ser más reflexivo y este es el origen de este escrito. He participado en algunas propuestas del Convenio Andrés Bello, otra entidad que me ha aportado una mirada internacional de la educación desde algunas experiencias en sus países miembros.

En conclusión, mis procesos praxeológicos vienen de la selva chocoana, para posicionarse en las grandes urbes como Bogotá, lo que no ha sido fácil y de lo que me siento orgulloso.

\section{La devolución creativa}

Es necesario que los hijos le devuelvan a la tierra aquello que les ha aportado, es necesario devolverle 
al pensamiento lo pensado, es bueno devolverle a la educación lo educado, es bueno devolverle a la humanidad aquello que te ha humanizado, por tanto la devolución creativa debe ser un acto retrospectivo y envolvente muy distinto a lo que le prohibieron a Lot, puesto que mirar hacia atrás genera identidad y hace posible fortalecerse en el hoy y para el mañana.

Este ejercicio ha sido muy importante, en la medida que me ha posibilitado la reflexión de mi vida y el encuentro con actores que probablemente ya había olvidado. Por otra parte, en algunos momentos hubo que parar este ejercicio para dialogar con mis hijos y contarles estas vivencias, lo que obligó a hablarles en algunos momentos del papel de los afrodescendientes en la construcción del país y de la discriminación a partir de los procesos de esclavización, donde no teníamos, ancestralmente, derecho a estudiar.

Contarles como la Citolegia fue la cartilla donde mi abuelo Pedro Pablo, llamado afectivamente Perucho, aprendió a leer y como la pizarra fue su cuaderno. Francisco, mi hijo menor, me preguntaba que si tenían una pizarra para cada materia y le dije que era una sola y que además tenían que borrar, me preguntó que entonces cómo hacían las tareas a lo que le respondí que las escribían, las presentaban y al día siguiente tenían que borrar, luego concluyó que entonces había que tener una excelente memoria.

Lo anterior también nos llevó a la reflexión sobre el origen de algunas expresiones de los afrodescendientes, en el sentido de que no pronunciamos algunas letras por economía lingüística, lo que nos llevó a leer algunos a partes de un libro sobre estudios de expresiones de los habitantes de San Basilio de Palenque de Nina de Frideman y Carlos Patiño Roselli ${ }^{12}$. Desde la revisión de algunas frases investigadas por estos autores, les mostraba que el origen de la economía ligüística en nuestra cultura se derivada de vestigios de lenguas africanas, por ejemplo: "kuando sé nasé, sè ta to yenito" lo que significa: "cuando se nace, está todo llenito".

Desde esta reflexión también mis hijos hicieron preguntas sobre el Chocó y algunos cuentos, lo que me obligó a presentarles un libro, el que Ana María ya había leído algunos cuentos pero no Francisco, quedando impresionado con un cuento del Profesor Miguel Ángel Caicedo, poeta chocoano ya fallecido titulado "El guapetón” y encontró en la lectura a un personaje que era el más fuerte y que había sido ombligado $^{13}$ con anguila, lo que lo hacia resbaloso y escurridizo cuando de peleas cuerpo a cuerpo se trataba, entonces Francisco me dijo que cuando fuéramos al Chocó quería que lo hiciera obligar con anguila y le respondí que se lo prometía.

Desde el punto de vista de la formación docente, no creo que el haber nacido al frente de una escuela hubiese sido el origen de formarme como maestro porque el maestro no nace, ni se hace en la experiencia, el maestro se curte en la praxis y es allí donde este ejercicio adquiere gran importancia, para todo aquel que quiera encontrar sus orígenes en la docencia y la forma de cualificarse en esta profesión.

En conclusión:

- El educarse en contextos interculturales se convierte en fortaleza, en la medida que se asume a los otros como pares, lo que implica su no concepción ni como superiores, ni como seres inferiores, simplemente somos seres humanos.

- La formación en la primaria y los aportes educativos inciden, en gran medida, en el momento de optar por la carrera docente, generando huellas en nuestra constitución como sujetos de la educación.

- Todo maestro debería alguna vez construir su historia de vida, pues es una buena alternativa praxeológica que fortalece la identidad profesional.

- En el proceso educativo, el diálogo con los abuelos genera grandes fortalezas educativas. 


\section{UNA HISTORIA DE VIDA Y UN EJERCICIO DOCENTE LEÍDO DESDE LA PRAXEOLOGÍA} POR: SIMÓN PÉREZ HERRERA ${ }^{14}$

$\mathrm{R}$ ecuerdo con precisión la escuela donde aprendí los números y a leer: mi casa. Con la tutoría de mis familiares; muchas veces de mi abuela, otra de mi madre, muy pocas de mi padre, y con ellos, la de mis primos, tíos, amigos nuestros y de mis progenitores, que llegaban a mi rancho todas las tardes, de lunes a viernes, como abejas al panal. Era tradición esa romería de gente a casa para hablar de todo sin dramatismos: de lo humano y lo divino, de los vivos y los muertos, de lo real o imaginario; todo ello con un trasfondo de camaradería, familiaridad y mamadera de gallo, donde se recreaba y narraba el mundo, las personas y los acontecimientos, y por supuesto, la forma de aprender. Así era. La enseñanza se alternaba con las risas, historias y humor de los adultos con la severidad que éstos imponían a los concursos académicos casi diarios, entre los niños que aprendían en sus casas y los que estaban en la escuela. La competencia giraba en torno a la escritura con caligrafía, las cuatro operaciones matemáticas y la lectura; el jurado era el batallón que nos visitaba. El aprender como la fiesta era una cuestión institucional en la vida cotidiana de mi pueblo y mi casa, que en el corredor de mi hogar, algunas veces, en el patio, otras, y en la calle, casi siempre, se daban como encuentros de amistad y de alegre aprendizaje que duraron muchos años.

No hay duda, mi familia era ese batallón que llegaba a comadrear casi siempre a las cinco de la tarde, cuando el sol comenzaba a "reposar", el calor a disiparse y los “animales de pico”, los mosquitos, mamá así los llamaba, que aparecían como plagas, y que los asistentes mataban a montones con las manos y los musengues de palmas, e inmediatamente amontonaban en el centro del círculo de ese combo dicharachero, para después "quemar a esos miserables puntiagudos que nos dejan tremendas ronchas”, decían, mientras se rascaban los brazos, las piernas y la espalda.
Más tarde entré a la "escuela de doña Rita”, como popularmente se conoce. Quedaba a cuatro casas de la mía. La severidad y el temor que inspiraba la profesora a los pupilos lo expresaban estos con una dócil obediencia y cabeza continuamente inclinada; muy poco nos atrevíamos a mirar a la profesora porque el carácter ácido de ella nos amedrentaba. A pesar de ello, la profesora era amiga, alegre, cordial y respetuosa con nuestros padres. Con los alumnos era toda severidad, y esta actitud era compartida por los padres de familia. Pero en mi caso, ila alegría de aprender y de ir a la escuela la metieron al refrigerador hasta nueva orden! Sin embargo, nuestros padres apoyaban el método porque, a fin de cuentas, se aprendía, aunque los castigos fueran severos: arrodillada de horas, algunas veces sobre granos de maíz, ladrillos en la cabeza, correazos, ridiculización ante los compañeros y, puesta al sol, en horas de calor infernal. A mí me dieron correa, pero tenía reconocimiento académico ante la profesora y los bebés que estudiábamos en esa escuelita, pues, muchos no pasábamos de seis años. Los que estudiamos allí recordamos esas experiencias actualmente con humor, risas, y algunos fogonazos de tristeza. Curiosamente, muchos estudiantes que recibieron esos castigos, y que ahora son padres de familia, matriculaban a sus hijos en ese lugar "porque se aprendía y se disciplinaba de verdad". Es decir, hay una exigencia colectiva de disciplina en el aprender y disciplina de vida al estudiante, que se espera tenga carácter de perennidad ética y profesional, y uno de los medios para lograr la perennidad la institucionalización del castigo que tenía respaldo social.

Luego me matricularon en la Escuela Alonso de Heredia. Pasé a segundo de primaria. La profesora, entrada en años, siempre sonreía; era respetuosa, 
dedicada, maternal y profesional con sus estudiantes. iMe fue excelente! iVolví a ser feliz en el estudio y la escuela! Terminé la primaria en ese centro. Los docentes en su mayoría exigían disciplina personal y académica. Ellos eran respetados y valorados por los padres de familia, por el pueblo momposino y sus alrededores: la persona y el rol docente tenían reconocimiento social, lo mismo que los centros educativos. La persona educada, es decir, la que tiene educación y enseña, se privilegia, se referencia socialmente porque el colectivo valora su ser persona, su profesión, ya que por ella se construye sociedad y seres humanos, realidad ésta que apoya el entorno social como una esperanza real, que otros estamentos sociales e institucionales han demorado. Por tanto, al docente y la educación se le perciben como un patrimonio de posibilidades $y$ aspiraciones sociales que iluminan y concretan caminos para la vida, la construcción y el ascenso social, a partir de un sólido compromiso de los docentes en su parte académica, humanística, social y ética que la comunidad de ese entonces avalaba al atorgarle una autoridad casi ilimitada a los docentes sobre sus hijos y las formas de enseñanza, ya que aquellos esperaban y creían que todo ello redundaría en beneficios de sus hijos, es decir, los padres de familia y la comunidad de ese entonces sí creía en las posibilidades de la educación para cambiar las situaciones de pobreza y estancamiento social que se vivía en ese medio: había esperanza y confianza en la institución educativa y en los maestros.

Después entré al bachillerato, al Colegio Nacional Pinillos, una institución de prestigio académico, ético y ciudadano. Esta institución era la cima del reconocimiento y el respeto en la zona y a nivel nacional, sobre todo en sus años dorados, que transcurrieron entre su inauguración en 1809 , hasta finales de la década de los 60s, en pleno siglo $\mathrm{XX}$, ya que era colegio universidad, por la calidad de su formación, sus docentes y la comunidad estudiantil, a estos últimos les admitían en las univer- sidades públicas del país, sin presentar examen de ingreso. Muchos de los más destacados estudiantes del Pinillos o "pinillistas", llegaron a ser docentes de la institución. Llama la atención la insistencia en la investigación por parte de estudiantes, docentes, padres de familia y ciudadanos de la región en el período mencionado del colegio, pues actualmente el investigar es un pilar de la política de educación en Colombia.

La relación con los docentes era cordial y de exigencia, todo ello rodeado de un ambiente convulsionado de protestas estudiantiles revolucionarias que eran sofocadas por el aparato de seguridad del gobierno de turno. Recuerdo el retraso de una protesta estudiantil porque teníamos clase con un profesor eminente de la época dorada del Pinillos. Los líderes estudiantiles llegaron al salón con algarabía para que nos uniéramos a la marcha. Un representante del salón le expuso "que después de la clase nos uniríamos". Mientras tanto, el profesor esperaba sereno la respuesta de los compañeros, con su habitual cigarrillo en la mano y recostado a la ventana del salón que daba a la calle. El maestro sabía que lo dejarían terminar, como nosotros y los líderes estudiantiles comprendíamos que apoyaba la huelga. iAsí de influyente era la presencia y la prestancia de los buenos maestros que lograban hacer un paréntesis en una "imparable" huelga estudiantil de más de cinco mil estudiantes de las tres jornadas! Aquí residía la autoridad del maestro ante sus alumnos: profundidad de su saber, sensibilidad social y humana, por un lado, y la cercanía a los estudiantes, que le permitía una visión más humana y situada de la vida de éstos y del contexto, por otro lado.

En el bachillerato me fue regular, pero aprendí mucho a nivel personal; en ese entonces existían muchos problemas de tipo socio-político, educativo, represión y otros, como también, se empezaban a dar los enredos del corazón juvenil, de las fiestas, los viajes aventureros, que distraían los compromisos académicos, y por último, estaba la desorientación de los 


\section{CONOCÍ AQUÍ LA PROPUESTA DE LA PRAXEOLOGÍA, QUE EN EL DISCURSO DE DOCENTES Y ESTUDIANTES ES EL PAN DE CADA DÍA.}

educandos que, aprisionados por las tenazas de las circunstancias adversas, se preguntaban sobre su futuro cuando terminasen el bachillerato. Recuerdo que el profesor de física preguntó qué íbamos a hacer después de terminar los estudios. La mayoría respondió "que se regalaría para el cuartel porque no podemos pagarnos la $U$ ". Otros respondían, "lo que salga”. Estos últimos quedaron a merced de los intereses de los barones de la politiquería, de los gamonales del pueblo y del infierno de la falta de oportunidades de Mompós. Los pocos trabajos eran de "corbata", mal remunerados y ocasionales en el municipio. Esto trajo mucha pobreza y frustración a mis compañeros de aula.

La amistad con los sacerdotes de Mompós fue una luz en mi camino. Los clérigos combinaban magistralmente lo espiritual - social y académico. La mayoría eran de Bogotá, pertenecientes a la comunidad religiosa claretiana. Eran respetados, pero cercanos a la gente, sin mucho protocolo, nada acartonados, quizá por el tiempo que llevaban en el Caribe. Eran respetuosos y solidarios con el pueblo. Los diálogos académicos y espirituales todas las noches después de la misa de siete de la noche, eran para mí un bocado de dioses. En el balcón de la casa cural, que daba a una de las plazas principales del pueblo, la Concepción, conversábamos sentados en una mecedora momposina, deleitándonos con la soledad y silencio de la plaza y el reflejo de la luna en las aguas tranquilas del brazo del río Magdalena. Seis años de diálogos con los clérigos, el trabajo que hacían en las comunidades, en los que participé muchísimas veces, me animaron a entrar al seminario.

Cuando reflexiono sobre mi estadía en el Colegio Pinillos me doy cuenta de que la situación del alma mater había cambiado porque la añoranza pesaba más en la percepción colectiva, un halo de tristeza y frustración se evidenciaba en las voces quebradas de las personas cuando recordaban el prestigioso centro educativo. El abandono estatal, los puestos recomendados para dirigir el colegio por parte de políticos corruptos, la diáspora de los mejores cerebros del colegio, que llevaban consigo una alta ética, una sólida ciencia, una formación social y ciudadana, además de las construcciones de colegios de secundaria en los distintos municipios de la región, y otros, opacaron al Colegio Pinillos. Al irse marchitando el colegio se afectó lo que representaba: la institucionalidad de una identidad colectiva en lo moral, ético, académico y ciudadano. Esto fue un golpe de muerte en la autoestima, el orgullo, la esperanza y la cohesión de valores sociales y ciudadanos de la región. El colegio dejó de ser la identidad cultural, el guardián de las instituciones públicas de Mompós y la esperanza de los pobres que buscaban redención en la educación.

Los lazos estrechos que existieron en el binomio institución del Pinillos -región momposina lograron una visión de ser humano, de sociedad y cultura, a partir del faro humanístico, ciudadano, ético y académico de esta institución educativa. Creo que a esto se le debe llamar devolución creativa asertiva. Esto es en definitiva una manera de concretar efectivamente la praxeología en el entorno. Actualmente hay discusión en diferentes lugares del país y del mundo, donde están regados los pinillistas para recuperar el colegio.

Posteriormente, entré al Seminario Regional Juan XXIII. Fue una experiencia excelente. La disciplina académica, la amistad entre seminaristas y sacer- 
dotes, la calidad académica, religiosa y humana de los formadores me abrieron horizontes inimaginables: amor por el Señor Jesús y su propuesta de vida, sensibilidad social, gusto fanático por los libros e interés por la enseñanza. Los padres formadores eran progresistas, comprometidos hasta los tuétanos con lo religioso, lo humano y lo social; allí entendí que estos elementos son inseparables para convivir y entender a los seres humanos, por supuesto para enseñar. Entre los docentes tuve al padre Carlos Juliao, llamado el "flaco o mono", quien tenía mucho arraigo en la comunidad estudiantil. Nunca lo vi participando de ningún campeonato, era más bien un espectador medianamente bullanguero, adicto al cigarrillo, al vallenato, a García Márquez, a la lectura en general y a no joderle la vida a nadie.

El seminario está ubicado en Sabanilla, en el municipio de Salgar, a treinta minutos de Barranquilla. Construido en la cima de un pequeño monte cerca al mar; donde la brisa y el paisaje marino formaban parte de la personalidad, la formación y orientación del seminario que, junto con los sacerdotes formadores, de mayoría cachaca, y de un número considerable de seminaristas de las tierras del interior, le daban a ese semillero sacerdotal una linfa, un espíritu y un sello distintivo del que todos participábamos y construíamos: el sabor y la identidad caribeña.

Desde que llegué a Bogotá en el 2000 me vinculé a la Uniminuto como docente. Ha sido una experiencia muy positiva. La mayor parte del tiempo he trabajado con la Facultad de Educación. Conocí aquí la propuesta de la Praxeología, que en el discurso de docentes y estudiantes es el pan de cada día. En este escrito he intentado realizar una hermenéutica de mi historia de vida, desde mi proceso de formación, cuando era estudiante, hasta ser docente actualmente de la Uniminuto. Para ello he recurrido a la memoria histórica, en ella he descubierto e interpreto mi entorno educativo, juntamente con las prácticas sociales y educativas propias y la de otros agentes (comunidad educativa y comunidades) que han estado implicadas en mi génesis, desarrollo y formación.

En estos siete años de labores educativas en la Uniminuto he intentado resaltar el agente, en este caso los estudiantes, como seres eminentemente históricos que se construyen, o buscan su construcción, en las interrelaciones, proyectos $y$ opciones personales, dentro de ambientes sociales y culturales definidos. Subrayo la relación agente-entorno como tensión-negociación- articulación-ruptura y re-creación. Dentro de esta relación se ve, juzga, actúa y hay devolución creativa, que son momentos de la praxeología, y en la que los agentes pretenden ser en el mundo y forjar mundos que, a su vez, reflejan propuestas antropológicas y societales, desde una praxis pragmática y educativa. La construcción personal como social, implican de manera categórica que la acción humana de los agentes (estudiantes), es la forma como construyen y despliegan su individualidad y proyecto personal, por un lado, como proyectos sociales y de comunidad, por el otro. Con la acción humana los agentes se concretan, pueden concretar sus intencionalidades y proyectos en el devenir histórico e incidir en éste último. Por ello, subrayo que la praxis que ellos realizan tienen un alto contenido social y político porque repercute en el entorno y su imaginario colectivo; subrayo que de sus praxis dependen los procesos sociales que generarán formas de organización y proyectos sociales; enfatizo que la calidad y pertinencia de sus praxis educativas capitalizan sus proyectos personales, la profesión docente, la educación, que es una de las formas como puede expresarse la devolución creativa a la sociedad, y, a su vez, esta capitalización sea un posible instrumento de negociación serio ante el estado, y de confrontación con el neoliberalismo, para posicionar y lograr el respeto que el docente $y$ la educación merecen y realizan: ser constructora $y$ formadora de sociedad y de seres humanos. 


\section{FORMACION DOCENTE Y PRAXEOLOGÍA PEDAGÓGICA}

POR: ROBERTO HERRERA CORREA ${ }^{15}$

"Me gusta ser persona porque, como tal, percibo a fin de cuentas que la construcción de mi presencia en el mundo, que no se consigue en el aislamiento, inmune a la influencia de las fuerzas social, que no se comprende fuera de la tensión entre

lo que heredo genéticamente y lo que heredo social, cultural e históricamente, tiene mucho que ver conmigo mismo"

Paulo Freire.

\section{Yo maestro}

$\mathrm{P}$ or sobre toda consideración personal y profesional, el maestro es un ser humano, que ha comprometido todo su ser al servicio de las personas. Su integralidad está presente en la historia de la humanidad, pues se constituye en el guardián de la civilización como intelectual de la cultura. Su vida y su obra educadora son actos de amor, como dice Freire. Amor por sí mismo e indudablemente amor por todo lo humano; su verdadera pasión, lo social, el encuentro con los otros-yo, la re-creación de la vida en la condición humana, otro apropiado, otro, puesto en su propio ser de maestro.

Constructor de calidad vida, predicador del bien-estar para todos; palabra constituida en diálogo; sujeto político impregnado de sentido participativo y democrático, enemigo de la opresión y la miseria humana, como lo señala Freire (2001): "ya no fue posible existir sin asumir el derecho o el deber de optar, de decidir, de luchar, de hacer política. Y todo eso nos lleva de nuevo a lo imperioso de la práctica formadora, de naturaleza eminentemente ética”.

Por ello, todos los seres humanos tenemos derechos fundamentales por tanto tenemos valores fundamentales: calidad de vida, libertad de palabra, pensamiento y acción; igualdad sin competencia, desarrollo integral de la personalidad, oportunidad de invención y creación, libertad de asociación y aprendizaje; uso irrestricto del talento, justicia y solidaridad social.

Considero un gran acercamiento conceptual entre lo planteado por Morin y Freire, en sus teorías educativo-pedagógicas. Por ejemplo, el reconocimiento del destino humano y social, como lo señala Morín: "El ser humano es un ser racional e irracional, capaz de mesura y desmesura; sujeto de un afecto intenso e inestable; él sonríe, ríe, llora, pero sabe también conocer objetivamente; es un ser serio y calculador, pero también ansioso, angustiado, gozador, ebrio, extático; es un ser de violencia y de ternura, de amor y de odio; ...se alimenta de conocimientos comprobados, pero también de ilusiones y de quimeras".

El maestro es un profesional cuyo campo de vida es la educación, por tanto su formación personal y profesional se constituyen en su ética de trabajo y servicio, en tanto estudia y problematiza los campos de la formación docente, que en términos generales, se denominan formación pedagógica, considerada la disciplina fundante de la formación del maestro; la investigación educativo-pedagógi$c a$, reconocida como el campo epistemológico del descubrimiento, la problematización y la innovación; la práctica educativa como vivencia cotidiana del quehacer docente, por tanto saber teórico y saber práctico, coherencia o conflicto; un conocimiento especializado, proveniente de las ciencias de la educación al que podría denominarse énfasis, y que está determinado por el gusto personal del maestro, por una disciplina particular de estudio; las reconocidas metodologías de enseñanza, tan complejas como cambiantes por razones como la diversidad de los grupos humanos, sus propias 
características y los contextos socio-culturales de la institución educadora, llámese escuela, colegio, universidad.

La profesión del maestro es testimonio de vida. Esa es la labor del maestro, ese es su verdadero compromiso. La comunicación es un diálogo fraterno, sincero y respetuoso, que puede utilizar todos los sistemas y caminos creados por el hombre para su encuentro

\section{Mi formación}

Indica Morin que "la cultura está constituida por el conjunto de los saberes, saber-hacer, reglas, normas, interdicciones, estrategias, creencias, ideas, valores, mitos que se transmiten de generación en generación, se reproduce en cada individuo, controla la existencia de la sociedad y mantiene la complejidad sicológica y social. No hay sociedad humana, arcaica o moderna que no tenga cultura, pero cada cultura es singular”. Así, siempre hay la cultura en las culturas, pero la cultura no existe sino a través de las culturas, la praxis misma, el encuentro, el momento de solidarizar la reflexión y encontrar planteamientos para superar las situaciones sociales conflictivas, de alienación, dominación y explotación, es decir, una educación elaborada como la práctica de la libertad, de la liberación del hombre por el hombre.

Freire fue creando en su discurso y en su práctica el pensamiento de una acción educativa que permitiera a los obreros y campesinos, a los hombres y mujeres del pueblo, comprender los entramados complejos de la política y la economía, cultura y su definitiva y marcada intervención en la educación, por ello afirmaba: "la alfabetización, y por ende toda la tarea de educar, sólo será auténticamente humanista en la medida en que procure la integración del individuo a su realidad nacional, en la medida en que le pierda miedo a la libertad, en la medida en que pueda crear en el educando un pro- ceso de recreación, de búsqueda, de independencia y, a la vez, de solidaridad."

Ahora recuerdo al maestro de la humanidad: Pestalozzi, quien, con su gran sensibilidad hacia los sentimientos y hechos de la humanidad, dedica su vida, sus conocimientos y pensamientos a la política, lo jurídico, literatura, religión, cultura, didáctica, educación y de manera particular a la pedagogía. Su mayor compromiso de vida: ser maestro de escuela. Éste es su mayor orgullo. Por ello dedica toda su vida a la educación del pueblo, en especial a la educación de los más necesitados, aun cuando recibió el grado de maestro a los 54 años, comenzando en mayo de 1800 su carrera de "maestro de escuela". Vale la pena recordar que Pestalozzi desarrolla sus pensamientos pedagógicos y educativos en cuatro instituciones Neuhof (1774-1780); Stanz (1799), Burgdorf o Berthoud (1800-1804), Yverdon (18171822). En las cuales va consolidando su formación de maestro y sobre todo sus estudios sobre el desarrollo del niño, su concepción pedagógica, la cual insiste en la conducción de los niños a la felicidad, lo que está relacionado con el desarrollo armonioso de todas las facultades del ser humano: cabeza, corazón y manos, que permitan la apropiación de formas, (geometría, caligrafía, dibujo), números, (aritmética) y palabras, (lenguaje, pensamiento); a través de didácticas que mencionan actividades de juego y actividades de trabajo, "es uno de los primero educadores en proponer y dar prioridad al SER sobre el tener. Critica duramente el saber verbal. Conserva el principio del humanismo al ver en el arte el fundamento de la educación, al incluirlo en su propuesta didáctica de las formas, donde la intuición hace parte de su psicopedagogía, desarrollada posteriormente por J. F. Herbart.

La educación, como acción humana, comprende que su desarrollo está fundamentando en la comunicación; es decir, el maestro, sin importar la modalidad educativa, que puede ser presencial, semipresencial, a distancia o virtual, siempre, indubitablemente, establece el proceso de formación desde los actos 
comunicativos, los cuales utiliza para evidenciar su formación personal y profesional, por tanto sus saberes y conocimientos, sus experiencias, sus descubrimientos, sus habilidades, como bien lo señala Humberto Maturana,(1994): “... Sostengo que los seres humanos existimos como tales en el lenguaje, y que todo lo que hacemos como seres humanos lo hacemos como diferentes maneras de funcionar en el lenguaje."

La comunicación es una interacción vital, trascendente; un pacto dialógico entre los miembros de una comunidad, que se comportan narrativos, discursivos y disertadores de la palabra; palabra plena de significado y significación, como lo plantea Freire (1998), "los hombres \{y mujeres\} no se hacen en el silencio, sino en la palabra, en la acción, en la reflexión. Más si decir la palabra verdadera, que es trabajo, que es praxis, es transformar el mundo, decirla no es privilegio de algunos hombres, sino derecho de todos los hombres $\{\mathrm{y}$ mujeres\}."

Cuando en la ruptura de los controles racionales, culturales, materiales hay confusión entre lo objetivo y lo subjetivo, entre lo real y lo imaginario, cuando hay hegemonía de ilusiones, desmesura desencadenada, entonces el homo demens somete al homo sapiens y subordina la inteligencia racional al servicio de sus monstruos"; mientras que Freire los va a plantear como pedagogía bancaria, pedagogía del oprimido, en la que traduce su saber socio pedagógico que implica la liberación tanto del oprimido como del opresor, como una postura integradora de teoría y práctica, que conduce a que la educación se rehaga constantemente en su praxis, es decir, en todos aquellos elementos que para ser, tienen que estar siendo; como la palabra verdadera que es trabajo, que transforma el mundo con poder insospechado al provocar el diálogo.

\section{Mi praxeología}

La práctica del maestro es un acto cotidiano, su diario vivir. El maestro desempeña el papel de un profesional práctico con un gran acervo teórico que proviene de las ciencias, las artes, las disciplinas científicas, el discurso pedagógico, la palabra y el saber del común, es decir, el conocimiento que proporciona tanto el mundo objetivo como el mundo intersubjetivo, que se constituyen en el escenario de la acción del maestro, como lo señala Nadeau, citado por Juliao, (2002), "la práctica es, entonces, un acto de interpretación que cada uno ejerce en primera persona situándose, con relación al mundo, en una perspectiva de un cierto proyecto de sentido."

En tanto el maestro interpreta, estudia y problematiza su propia praxis, va emergiendo la praxeología pedagógica, que desde sus sentidos hermenéutico-dialécticos permite aparejar la funciones de analizar, comprender, interpretar y aportar conclusiones a otras situaciones de la práctica educativa, para integrar en un mismo sentido teorías y prácticas, en tanto la reflexión y el contraste de opiniones, implican creación, otras posibilidades de conocimiento, a manera de lo que Porlán (1997) establece al señalar que "el profesor, en definitiva, puede criticar sosegadamente su conocimiento tácito y su reflexión espontánea durante la acción y para ello puede prever métodos y técnicas que le faciliten la recogida de información sobre los procesos reales del aula."

\section{LA PRAXEOLOGÍA PEDAGÓGICA ES UN PERMANENTE ESTADO DE INQUIETUD Y CUESTIONAMIENTO, UNA CONSTANTE REFLEXIÓN QUE INTENTA UN RE-HACER INVESTIGATIVO}


Es decir, estudiar e investigar la práctica es una nueva oportunidad de aprendizaje, un des-aprender lo ritual y estereotipado, un dotar de significados diferentes a la educación, de acuerdo con Juliao (2002), "el aporte real de la praxeología es haber hecho de la participación y de la comunión (cooperación) la dinámica del proceso formativo, asignando a la praxis, a la acción humana con sentido, el lugar que le corresponde en la creación y la reproducción del conocimiento."

Condición humana, formación humana; absoluto respeto y compromiso por la vida, insisto, esa es la verdadera labor del maestro, ese es su verdadero compromiso ético. Así lo indica Freire: "El hombre dialógico tiene fe en los hombres antes de encontrase con ellos. Esta, sin embargo, no es una fe ingenua. El hombre dialógico que es crítico sabe que el poder de hacer, de crear, de transformar, es un poder de los hombres y sabe también que ellos pueden, enajenados en una situación concreta, tener ese poder disminuido."

Ahora bien, afirma Eloisa Vasco (1998) que "el maestro está permanentemente expuesto a caer en la rutina. Este es uno de sus 'riesgos ocupacionales', y quizá el más peligroso, por lo mismo que es cotidiano." Es así que la praxeología pedagógica convoca al maestro a no caer en la rutinización de su vida profesional, en la absurda comodidad y quietud de la inercia del que todo lo sabe. La praxeología pedagógica es un llamado constante y permanente a la renovación personal y profesional, a la sospecha del conocimiento inmóvil y finito; a vivir la incertidumbre del cambio rápido y audaz, a la búsqueda del nuevo día; al reconocimiento, siempre renovado, de la complejidad del ser humano; a la capacidad de asombro, a dejar atrás la tradición vacía y carente de sentido, a encontrar un nuevo paradigma.

Parodiando a Sagan (1998) en El Mundo y sus demonios, capítulo "No hay preguntas estúpidas", la praxeología pedagógica es un permanente estado de inquietud y cuestionamiento, una constante reflexión que intenta un re-hacer investigativo, pues en tanto el maestro se cuestiona sobre su formación, conocimiento y práctica podrá renovar sus caminos y problematizar la educación y la pedagogía. Tal vez entonces las preguntas no tendrán respuestas simples, acomodaticias; serán verdaderas preguntas-problemas que pondrán a prueba los sentidos de la formación teórica y práctica del maestro.

El problema del conocimiento es un problema de vida del maestro, como lo afirma Juliao (2002), "es necesario considerar la investigación praxeológica, la reflexión sistemática sobre la propia práctica, en especial cuando uno de los más graves problemas de nuestro tiempo es la falta de reflexión sobre lo que hacemos."

Se puede afirmar con Zuleta (1994) que "el atractivo terrible que poseen las formaciones colectivas que se embriagan con la promesa de una comunidad humana no problemática, en una palabra infalible, consiste en que suprimen la indecisión y la duda, la necesidad de pensar por sí mismos...” No. La praxeología es un pensar problematizador de la vida, una metodología que devela los actores y sus acciones, sus palabras explícitas y ocultas; las relaciones de orden y poder de un grupo social, el sentido de la acción política y su ideología subyacente. Es decir, re-estudiar, re-crear, re-inventar, re-hacer, se constituyen en una preocupación constante de la formación del maestro, en tanto el acto de estudio de sus teorías y prácticas, en particular de estas últimas, se constituye en problematizaciones que alteran sus formulaciones y discursos pues conllevan la transformación de sus formas de pensar, actuar y hacer.

Como lo plantea Juliao (2002), "la investigación praxeológica pretende cualificar las prácticas, introducir cierta racionalidad en las prácticas, ayudar a sistematizar, generar capacidad para transformar la realidad”. La praxeología pedagógica se constituye en 
la postulación a la formación de un nuevo educador colombiano: ético, libertario, demócrata, pluralista, disciplinado, amoroso y apasionado por su vida de maestro, por la vida y los seres que habitan el universo; por el conocimiento científico y popular; comprometido por una educación liberadora para todos los ciudadanos de la tierra, como bien lo afirma Freire (1999): "La opción, por lo tanto, está entre una 'educación' para la domesticación alienada y una educación para la libertad. 'Educación' para el hombre-objeto o educación para el hombre-sujeto."

Es así que para Friere la educación es un intento constante por el cambio de actitudes, de creación de espacios y tiempos democráticos en los cuales el acceso a la reflexión y la toma decisiones sean pluralistas y divergentes, cargada por el debate de ideas y acciones, en donde la palabra sea vital, trascendente, toda una praxis educativa cargada de contemplación y no de simple retórica y palabrería hueca. Es decir, una educación libertaria diferente a la asistencialista, repetitiva, vacía, "teórica", podría decirse retórica, facilista y descontextualizada. Existe la diversidad humana; a lo que Morín va a señalar "la diversidad no está solamente en los rasgos sicológicos, culturales y sociales del ser humano. Existe también una diversidad propiamente biológica en el seno de la unidad humana; no sólo hay una unidad cerebral sino mental, síquica, afectiva e intelectual. Además, las culturas y las sociedades más diversas tienen principios generadores u organizadores comunes".

La educación misma, la escuela o el aula se convierten espacios educativos que pueden ser problematizados y a la vez investigados, en un serio intento por superar las dualidades de teoría y práctica, las cuales, en muchas ocasiones se convierten en espacios vacíos y al desarrollar, carentes de sentido, sus contenidos curriculares, las más de las veces impuestos por el establecimiento o por agentes ajenos, los cuales obran y piensan la educación desde las trincheras de la mera producción comercial, las cuales conducen a las comunidades educativas a realizar lecturas de un mundo alienante y acomodaticio de ideologías de poder, ajeno a sus propias realidades.

Se puede afirmar que la sociedad ha creado la escuela como institución educativa para formar a las generaciones jóvenes, por tanto, la escuela se constituye en el espacio cultural por excelencia y su importancia está estrechamente relacionada con su continua transformación, con la apropiación y problematización de saberes y conocimientos, con sus propuestas de formación integral de las comunidades educativas y con la cualificación de la vida humana misma. Indica Comenio que la escuela debe estar a cargo del Estado, en un serio llamado a la educación conocida como pública y la cual, por las políticas del neoliberalismo, hoy se ve seriamente amenazada, vilipendiada y desprestigiada, pues a la escuela se acude cuando las personas e instituciones cometen actos inadecuados, como si la institución contará con programas educativos que atentarán contra las personas o la sociedad.

La coherencia alcanzada entre el decir y el hacer, como elementos importantes de la identidad personal y profesional, se constituyen entonces en testimonio, que válida las palabras y los hechos del maestro, son factores de identidad. No parece suficiente el saber decir, también es necesario el saber-hacer, la forma como se viva y se asuma la vida, identificarán, como códigos descifrables, la razón de la existencia del maestro. Parodiando a Freire, "la praxeología pedagógica debe emerger empapada de teoría y práctica, en colectivos de maestros en donde la discusión de teorías y prácticas permitan develar y cualificar los procesos de conocimiento y formación tanto de educandos como de educadores, como seres que afectan y son afectados por muchas relaciones de la más variada índole que les permiten conocer sus potencialidades y limitaciones". 


\section{Y LAS FLORES FUERON TESTIGO}

POR: YolandA VILLARROEL CORONADO ${ }^{16}$

$\mathrm{E}$ calor propio de la región caribe que domina siempre el ambiente de todos aquellos que hemos tenido la fortuna de nacer cerca del mar, marchita flores e inunda de color amarillo pálido los terrenos cercanos a las viviendas. Sin embargo, las voces alegres y bulliciosas de los niños que ajenos a la inclemencia del tiempo, juegan y sudan, son testigos de la capacidad del ser humano para adaptarse a los rigores del sol del mediodía. $\mathrm{Y}$ en ese ambiente se hace posible que una niña sueñe y sueñe con las flores como seres con alma y mente, con posibilidades de aprendizaje, frente a sus exigencias en su condición de maestra, que ve en las flores las caritas de niños y niñas a quienes hacia el futuro, puede enseñar. La tarea es difícil, no hay respuestas acertadas, no hay comportamientos adecuados, pero la paciencia de la niña casi consigue, en su imaginación, alcanzar los mejores logros y obtener las mejores respuestas. Las flores son compensadas con un riego abundante, pero eso sí las equivocaciones son severamente castigadas. Sólo el llamado de atención de los adultos, padres o hermanos, hace posible que sea interrumpido el escenario del aula en el jardín y el sueño se quiebre, transitoriamente. Este remoto recuerdo me permite considerar que, en el transcurso de nuestro devenir y en los procesos de formación humana y profesional, siempre se destacan aquellos espacios de juegos infantiles que enrutan nuestro futuro profesional.

En esas vivencias tomaron cuerpo las estrategias didácticas de la maestras de la primera infancia, con todas las gamas de posibilidades, de extremos agradables, experiencias amables y recuerdos gratos. Se unen además los recuerdos vívidos del espacio de las aulas y todavía más los ambientes del colegio, en el cual fue posible estudiar todos los años de primaria y bachillerato con un reco- nocimiento permanente de quienes somos, con las fortalezas en el campo de la declamación, el baile y las debilidades para la costura y la educación física. Todo este conjunto de aprendizajes se recreaban en el jardín y las flores como testigos mudos adquirían nombres y eran obligadas a contestar a la lista so pena de ser castigadas. La diversidad de flores era un reflejo de lo aprendido en las aulas del colegio, lo diferente se aceptaba y lo igual se respetaba. Las diferencias de credo, raza, ideologías, condición social y de nacimiento, no eran tenidas en cuenta como factor de discriminación. Ese ambiente de aceptación y de respeto, sembraron la tolerancia y la consideración hacia las debilidades y el reconocimiento de las posibilidades.

Los encuentros con el otro y un otro afectivo, distante en costumbres pero sabio, generoso, con inteligencia superior, hicieron que los sueños se postergaran y se construyeran otros sueños, diferentes, pero igualmente significativos. La construcción fue amorosa, tierna y compartida con un sentimiento profundo de amor un poco más intenso de un lado que del otro pero de cualquier forma de aportes mutuos, de aprendizajes y de esperanza. Pero el sueño se rompió, los dolores fueron enormes, las esperanzas se truncaron y lo que hasta el momento había sido una vida de risas y alegrías se convirtió en una sombra, se empañó con el dolor más profundo que pueda experimentar el ser humano, la pérdida temprana de un hijo. Sin embargo, ayudaron a la recuperación, la juventud, el apoyo de los padres, el consuelo de quien no se sentía ya capaz de consolar y el inicio de la formación académica para ser realidad el sueño primero, ya que el segundo se podía visualizar como imposible.

La llegada a Bogotá, para iniciar el proceso de formación en la Facultad de Educación de la Universidad Externado de Colombia, acompañada de experien- 
cias de enseñanza, pudiera describirse similar a lo descrito por nuestro célebre Premio Nobel, a su llegada a la zona andina. Sería atrevido intentar siquiera hacer un acercamiento a esa descripción pero la sensación del frío físico, la soledad, el alejamiento del mar, la distancia de los amigos, todo se conjugaba para hacer de ese proceso la experiencia de mayor entrega y dedicación, y es así como se obtienen los más altos reconocimientos académicos a lo largo de toda la carrera. Sin embargo, la posibilidad de conjugar la formación académica con el trabajo en el aula, brindaron las mejores posibilidades de confrontación entre lo compartido entre compañeros y docentes y lo experimentado en la escuela. Espacios y experiencias disímiles, seres humanos con concepciones sobre el mundo, el hombre y la sociedad, totalmente opuestas, sin embargo, con propósitos comunes y con metas similares. Estas vivencias, analizadas con mayor madurez, permitieron sin saberlo ni sospecharlo siquiera, crear los mejores espacios de crecimiento profesional y personal.

El inicio posterior del ejercicio profesional en la educación pública fue un camino largo y a veces desmotivante, pero siempre enmarcado por las expectativas de vida y de hacer realidad el sueño de las flores en la ya casi olvidada residencia solariega de la arenosa.

Los andares y avatares de cada ser humano son capaces de ir generando madurez, crecimiento, hay ires $\mathrm{y}$ venires, amores y desamores, tejidos sueltos pero también entramados fuertes que hacen valiosa toda vida humana. Es así como se encuentra una oportunidad, se da vida y se sanan heridas, se crece, se aprende y se apoyan procesos de crecimiento en los otros. El sueño es bello, la vida sonríe, la escuela permite dar aporte, se experimenta, se construye y se reelaboran posibilidades de unir lo separado y de volver a creer y a confiar.

Una hermosa oportunidad se pudo vivir, compartir la experiencia de construcción colectiva de procesos educativos, en una comunidad que consideró aplicar una metodología, aparentemente desconocida pero interesante $\mathrm{y}$ novedosa, basada en procesos denominados "ver, juzgar y actuar”. Al inicio, se dieron las dificultades propias de los cambios pero con el trascurso de los meses y dadas las bondades evidentes de esos procesos, la comunidad sintió que era aplicable a las condiciones de vida de la población y todos a una nos animamos a seguir construyendo posibilidades de trabajo desde el primer momento; el ver las experiencias, los procesos, las dificultades y las posibilidades, juzgar con mirada benevolente lo realizado, analizar con sentido crítico y el actuar como una oportunidad para hacer mejor las cosas pero siempre con compromiso firme, sentido de pertenencia y solidaridad . Este encuentro, más tarde se fundamentó en una propuesta que nos es familiar: la "praxeología pedagógica", el hilo conductor de un quehacer sin el saber, se unió con un saber para poder hacer.

El desempeño profesional permitió lo anterior, en distintos ambientes, con niños, niñas, jóvenes, adultos y dio lugar al aprendizaje mutuo y abrió la posibilidad de considerar que el oficio del maestro, siempre presente en las distintas comunidades, es una opción de vida en donde también las flores tienen una oportunidad. 


\section{HISTORIA DE VIDA DE UN MAESTRO}

POR: GERARDO BAZANTE CALDAS

\section{Introducción}

$\mathrm{L}$ a historia del magisterio está llena de sinsabores, soledades, desprecios e ignorancias ${ }^{17}$. Las decisiones políticas, los análisis sociológicos, los testimonios literarios, la imagen social o la propia conciencia y expresión de los protagonistas confirman esa crónica desconsideración hacia ese oficio tan viejo como digno ${ }^{18}$.

El maestro en nuestro medio fue un profesional respetado, pero con el paso de los años esto se fue perdiendo, el maestro se ha ido cansando de escuchar de boca de las administraciones palabras solemnes y grandilocuentes sobre la importancia de su "hacer" y a la vez comprobar en la práctica, los escasos apoyos y concesiones de aquel discurso retórico.

La docencia requiere cada vez de un trabajo con mayor complejidad, pero el maestro se ha convertido en el chivo expiatorio de todos los fracasos y deserciones escolares aunque únicamente le corresponda sólo una cuota menor de responsabilidad.

El docente ha tenido que vérselas en el transcurrir del tiempo con elementos y particularidades que afectan su labor:

- La extensión y generalización de la enseñanza ha supuesto también su masificación bajo el baluarte del uniformismo y la racionalidad, contempladas desde la fría óptica tecnocrática; sin la menor atención a amplios o reducidos colectivos escolares que, en razón de su contexto o de su historia particular, requieren un tratamiento diferenciado ${ }^{19}$. Para poner un ejemplo, la Ley General de Educación propicia la construcción de currículo por parte de los maestros de acuerdo con el contexto particular de la escuela, pero a la vez mide o estandariza la medición a los bachilleres a nivel nacional con el mismo rasero, léase Pruebas de Estado (ICFES). Esto contradice la autonomía y uniforma el nivel de conocimientos, irrespetando de alguna manera los procesos y los caminos o formas de llegar al conocimiento. De esa manera, el currículo dirigido sólo al alumno medio no deja de ser una falacia estéril cuando la escuela, para compensar las desigualdades de origen, debería integrar a todos y a cada uno de los estudiantes.

El crecimiento cuantitativo no ha venido acompañado del necesario desarrollo cualitativo. Esto sí marca una diferencia sustancial con la función docente de antaño.

- El proceso de enseñanza-aprendizaje crece en complejidad por varias razones: producción acelerada del conocimiento en todos los ámbitos de la ciencia y de la cultura; presencia de otras redes e instrumentos de aprendizaje que actúan como una auténtica escuela paralela (televisión, Internet, Tics); progresivo divorcio entre el saber académico y el saber científico, social y cotidiano; desintegración del ámbito educativo familiar y en su reemplazo la calle como ámbito de aprendizaje; contradicción entre la cultura escolar y la cultura del trabajo; éstos, entre otras, configuran una gama amplia de desfases.

Otrora, la escuela ostentaba el monopolio de la transmisión del saber y del proceso educativo; además, lo hacia sólo en unos espacios muy precisos y con recursos más bien escasos ${ }^{20}$.

En el presente, por el contrario, el maestro activo debe ser capaz de captar esos nuevos saberes, de 


\section{PEDAGÓGICA}

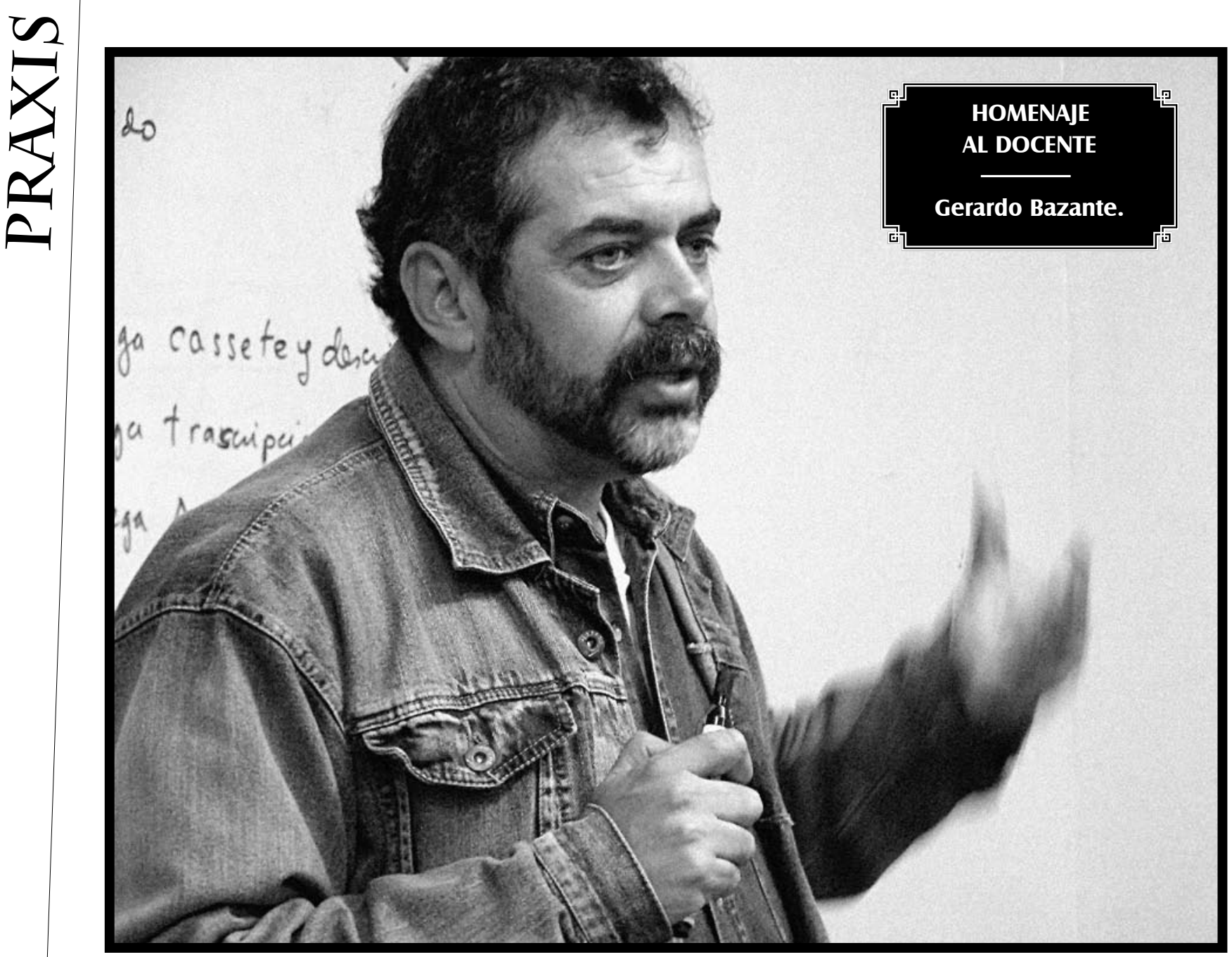

planificar su actuación recogiendo otros registros informativos, otras formas de pensar y variedad de recursos dispersos ${ }^{21}$.

La atención social y económica hacia la escuela en países como el nuestro, los recursos destinados para la educación en otras palabras, nunca han sido óptimos; las sucesivas administraciones han desestimado la producción de capital humano y por tanto desechado la confianza en el futuro deteriorando la cualificación técnica de los trabajadores, la producción de ciencia y tecnología; igualmente, se debiera exigir la transferencia de ciencia y tecnología como una prioridad para las empresas extranjeras que usufructúan nuestros recursos estratégicos, eso llevaría al desarrollo equitativo entre los países desarrollados y el tercer mundo, además del bienestar individual y colectivo. Hoy, cuando se im- ponen políticas de corte económico neoliberal, los gastos en educación están sometidos a un cicatero escrutinio y desviados para la guerra.

El maestro cada día ve disminuido su salario y su poder adquisitivo, sus condiciones de trabajo descienden hasta límites precarios y a veces lamentables. La crisis económica, y las otras crisis que la acompañan, agravan el deterioro de la imagen del profesor volviéndola cada vez menos atractiva a los ojos de otros profesionales, de los hipotéticos aspirantes y del conjunto de la sociedad.

De todas maneras, se hace necesario y urgente resaltar elementos importantes de aquellos seres que trascienden en su hacer, su autonomía y profesionalidad a pesar de las funciones diferenciadas 
y la progresiva complejidad que deben atender a partir de su pensamiento, su imagen y auto imagen; algunas características más específicas, como es la feminización de la profesión, la difícil andadura del maestro nuevo, el panorama sombrío de nuestro país en conflicto, la contradicción entre su formación inicial y el ejercicio como profesor afectan su desempeño; la entereza, la capacidad de entrega, el sentido de pertenencia y el compromiso cotidiano, en fin, la apuesta de su proyecto de vida se hacen cada vez más necesarios.

El interés de este artículo no es recrear el diagnóstico crítico acerca del profesor, significando sus múltiples miserias y contradicciones, la apuesta no es por determinismos insalvables sino más bien con fe razonable en las posibilidades de cambio en la escuela, desde dentro y desde fuera de ella.

La invitación por eso es a reflexionar, a mirar otras experiencias y orientaciones para ir revalorizando ese viejo pero digno oficio de maestro, para que algún día se haga realidad la frase de José Martí: "Educar es ante todo un acto de amor"22.

La escuela y el maestro piden, a gritos, nuevos enfoques, alternativos a su quehacer cotidiano, para su propia supervivencia afectiva y efectiva, y para descubrir horizontes donde sea posible un trabajo más digno, científico y creativo; la historia de vida que a continuación se relata, nos muestra a uno de esos seres que por su carisma se ha vuelto imprescindible, nos visualiza un panorama halagador para beneplácito de la escuela, de la comunidad educativa, de la educación y del país.

La historia del maestro Pedro Pablo Fonseca es un ejemplo de vida entregada a la labor docente. En el caso del "Dire", como le dicen a don Pedro en el colegio, uno podría decir que "el maestro nace y se hace"; el maestro Pedro Pablo es hijo de la violencia política de los años cincuenta, nació en el oriente del Tolima; su padre, un día, después de cargar madera y carbón para la cocina en su rancho campesino, bajó al pueblo y fue asesinado por el delito de ser cuñado del líder agrario Juan de la Cruz Varela; siendo Pedro aún niño, y el menor de seis hermanos, como consecuencia de eso fue desplazado y en el peregrinar de su familia llegó hasta la Uribe en el departamento del Meta, de allá regresó siendo aún niño y sin estudio, comenzó las primeras letras a los doce años de edad una vez pudo su familia retornar al Tolima.

En la formación del “Dire”, la primera que influyó fue su propia madre, ella lo envió para la Normal de Icononzo, una vez terminó su primaria, allá vivió solo, fue estudiante aventajado y logró culminar sus estudios alcanzando el título de Normalista. Una vez graduado recorrió varios pueblos de la cordillera central tolimense llevando las primeras letras a las escuelas veredales.

La práctica cotidiana lo convirtió en un experto en las lides de transmitir conocimiento, se casó con una docente y llegó a la capital para ejercer lo que sabía hacer: "enseñar".

En Pasquilla se convirtió en director de escuela y de allí pasó a la vereda el Retiro, zona rural de Usme, en el Páramo de Sumapaz, trabajó inicialmente con el programa Escuela Nueva, con tesón y entrega conquistó el corazón de niños, padres y maestros, su carisma y capacidad lo llevaron a ser el rector de la Institución Educativa Distrital el Retiro, a la que llegó como director porque era pequeña y sólo se enseñaban los cursos de primaria.

Un día, el "Dire” acompañó a Monseñor Vega hasta San Juan del Sumapaz, allá estaba la guerrilla y entre sus militantes encontró a algunos de sus egresados, al preguntarles el porqué se habían incorporado a este grupo, ellos contestaron, "nosotros no tenemos futuro, con primaria no más, no conseguimos trabajo, acá somos alguien"; el "Dire" habló con el comandante, al convencerlo regresó con algunos de los muchachos, ese día se comprometió 
con ellos a crear el bachillerato, entonces formó un ejército con la comunidad educativa, un ejército de paz, de estudio y trabajo, es decir, le quitó unos niños a la guerra, transformó las precarias instalaciones de la escuelita en un confortable edificio de dos plantas, con huerto para labores agrícolas donde se combina el conocimiento empírico de los padres con el técnico de los instructores del SENA, creó el campo para deportes, construyeron corrales, jaulas, porqueriza y lago, para la cría de animales, talleres, sala de sistemas, cocina y comedor comunitario, hoy atendido por madres y con la entereza y convicción que de esa manera se le sale al paso a la guerra y se eleva el nivel alimentario de la población.

Hoy, los egresados de las escuelitas de las veredas del Páramo tienen una institución sin la discriminación que tenían en el colegio urbano y no tienen pretexto para "coger monte", los niños que alguna vez fueron guerrilleros y el "Dire" rescató, hoy son bachilleres y lideran proyectos agropecuarios en el colegio.

Han pasado varios años, hoy el Instituto Técnico Agropecuario luce grande, los estudiantes llevan para su casa nuevas técnicas agropecuarias que enseñan a sus padres, llevan también gérmenes de buen trato y mucho amor.

Aunque la guerra siempre los acechará, hoy las opciones son otras, "el Dire", ha establecido convenios con la red de bibliotecas, con el SENA, además, buscó el Internet, seleccionó un gran equipo humano y con ellos trabaja en jornada doble, es un hombre comprometido, que irradia alegría y deseo por hacer las cosas bien.

Don Pedro bordea los sesenta años, es común verlo con su ruana y sus botas pantaneras brindando la mano amiga, el consejo oportuno, el abrazo cálido, con su temple a la hora de enfrentar tanto a guerrilleros como a militares; el caso omiso a las palabras cargadas de amenaza, los oídos sordos a los miedos infundados o verdaderos, el sentido de pertenencia, el compromiso con la comunidad y el arrojo frente a la adversidad lo han convertido en uno de esos seres imprescindibles para el entorno en el que se desenvuelve.

Con el paso de los años, el profesor Fonseca se convirtió en el líder de una comunidad que lo sigue porque conoce de su empeño en sacarlos adelante.

En su familia es un hombre común, su esposa es profesora y sus hijos: él, universitario y ella próxima a terminar su bachillerato, son reclamadores de tiempo, pero el "Dire", también los ha comprometido a ellos con el proyecto que lidera.

Finalmente, hay que decir que don Pedro nunca ha buscado reconocimiento, pero lo tiene bien merecido por ser uno de esos seres que con dignidad, orgullo y compromiso reivindica la noble profesión de docente.

Lo relevante de don Pedro es reconocerlo como gestor de proyectos de formación y transformación de las comunidades en las que ha participado.

Si por proyecto de vida se entiende el planteamiento hacia donde va nuestra vida, el norte, cuáles son nuestros sueños y cuáles los medios para lograrlos, una situación futura ideal que se materializa día a día, haciéndonos responsables de nuestro destino, cuestionando y evaluando nuestras metas a corto, mediano y largo plazo, el ser conciente de lo que se desea, el que uno clarifique sus objetivos y finalmente determine los medios, capacidades, habilidades y competencias para lograrlo con el concurso también del conocimiento de sí mismo y el compromiso total con lo que hace o sentido de pertenencia, de los talentos propios, las cualidades, las habilidades pero también las limitaciones y las debilidades personales, entonces podremos decir que don Pedro Fonseca es de esos hombres que han dejado huella, finalmente puedo decir como lo expresan sus alumnos a diario, gracias maestro o gracias "Dire", por lo que hace. 


\section{APROXIMACIÓN A LA PRAXEOLOGÍA. REFLEXIONES PERSONALES POR: LUCÍA ARDILA ROMERO 23}

"Solo sé que nada sé, y lo poco que sé, se lo debo a mi ignorancia"

Platón

$\mathrm{L}$ a primera vez que escuché la palabra PRAXEOLOGía estaba sentada en la reunión de inducción a los docentes recién vinculados a la planta de personal de la Facultad de Educación de la Universidad Minuto de Dios, (segundo semestre del año 2005), era un mirar la realidad desde una perspectiva diferente. Ese semestre no incursioné mucho en el tema, me parecía álgido, complejo, intrincado, me conformé con las ideas, un poco etéreas quizás, que había logrado captar, en ese primer coqueteo con lo nuevo.

Pero como sucede en la vida, todo aquel que coquetea termina de un modo u otro involucrándose con el objeto de su interés, y no fui la excepción; al siguiente semestre (primero del 2006), en la carga académica se me asignaba el eje temático INVESTIGACIÓN EDUCATIVA I, para acompañar a los estudiantes de VII semestre en la identificación de los presupuestos praxeológicos en el campo de la Investigación Educativa. La sorpresa fue grata a la vez que retadora. Entonces hice lo que todos aquellos, que de una u otra manera necesitan una tabla de salvación, porque sabiendo nadar, el río está tan revuelto que la orilla se pierde, los árboles no dejan ver el bosque; ipedí auxilio! y una mano amiga se tendió ante mi, la de la MAESTRA FANNY MORALES; así, escrito con mayúscula y en negrilla, porque junto con muchos otros que comparten conmigo el espacio pedagógico de la UMD, merecen llevar este título-, ella me presentó al PADRE CARLOS GERMÁN JULIAO VARGAS en su libro "LA PRAXEOLOGÍA: UNA TEORÍA DE
LA PRACTICA". Se inicia el andar y el desandar, el leer y el releer, buscando entre las hojas del libro la claridad conceptual que me permitiese asumir la formación investigativa de los estudiantes desde el MODELO PRAXEOLÓGICO. Ser investigadora social, aplicada a la educación, es mi acción y mi pasión, pero debía revisar para apropiarme de la teoría en busca del ejercicio práctico, porque si no lo tenía claro, ¿̇cómo lo orientaría? No se puede ayudar a construir un conocimiento que no se tiene. "No se puede enseñar lo que no se sabe" ${ }^{24}$.

En este trasegar autodidacta y recurriendo siempre a las ventajas de la memoria asociativa, un enlace se presentaba claro, las coincidencias eran relevantes y significativas, y éste sí era un paraje conocido, EL MÉTODO DIALÉCTICO, entonces entre una marejada de recuerdos surgen Manuel Sacristán y Fernando Claudín, analizando los presupuestos de la dialéctica vista como: "La filosofía es, pues, aquí, «superada», es decir, «tanto superada como conservada»: superada en cuanto a su forma, conservada en cuanto a su contenido real». Sacristán considera esta formulación justa pero un tanto general, susceptible de ser interpretada diversamente a la hora de su utilización concreta. Lo que en ella queda más claro es que para Engels lo filosófico se concibe «no como un sistema superior a la ciencia, sino como un nivel del pensamiento científico: el de la inspiración del propio investigar y de la reflexión sobre la marcha y resultados...». ${ }^{25}$

La investigación de la realidad, la reflexión sobre la marcha y los resultados; el ver, el juzgar, el actuar y la devolución creativa, se amalgamaban en un todo que cada vez era más nítido "análisis concreto de la situación concreta [Sacristán se ha referido antes a esta fórmula de Lenin, haciendo notar que el término 
'análisis' no tiene aquí el mismo sentido que en la ciencia positiva. F.C.], intento de comprensión de las realidades concretas con que trata el hombre, las cuales no son las ecuaciones diferenciales de la mecánica clásica, ni la ecuación de Durac, sino otros hombres, otros todos concretos y estructurados compuestos por hombres, estados concretos de la naturaleza, la resistencia y el apoyo concretos de ésta -la vida»"26. Investigación social contextualizada -así parezca redundante-, lecturas de la realidad educativa, ejercicios de reflexión sobre la práctica. Para mí era ahora fácil hacer la relación y anclar en la dialéctica la praxeología. Para otros, los nexos y los asideros conceptuales serán diferentes, pero en mi

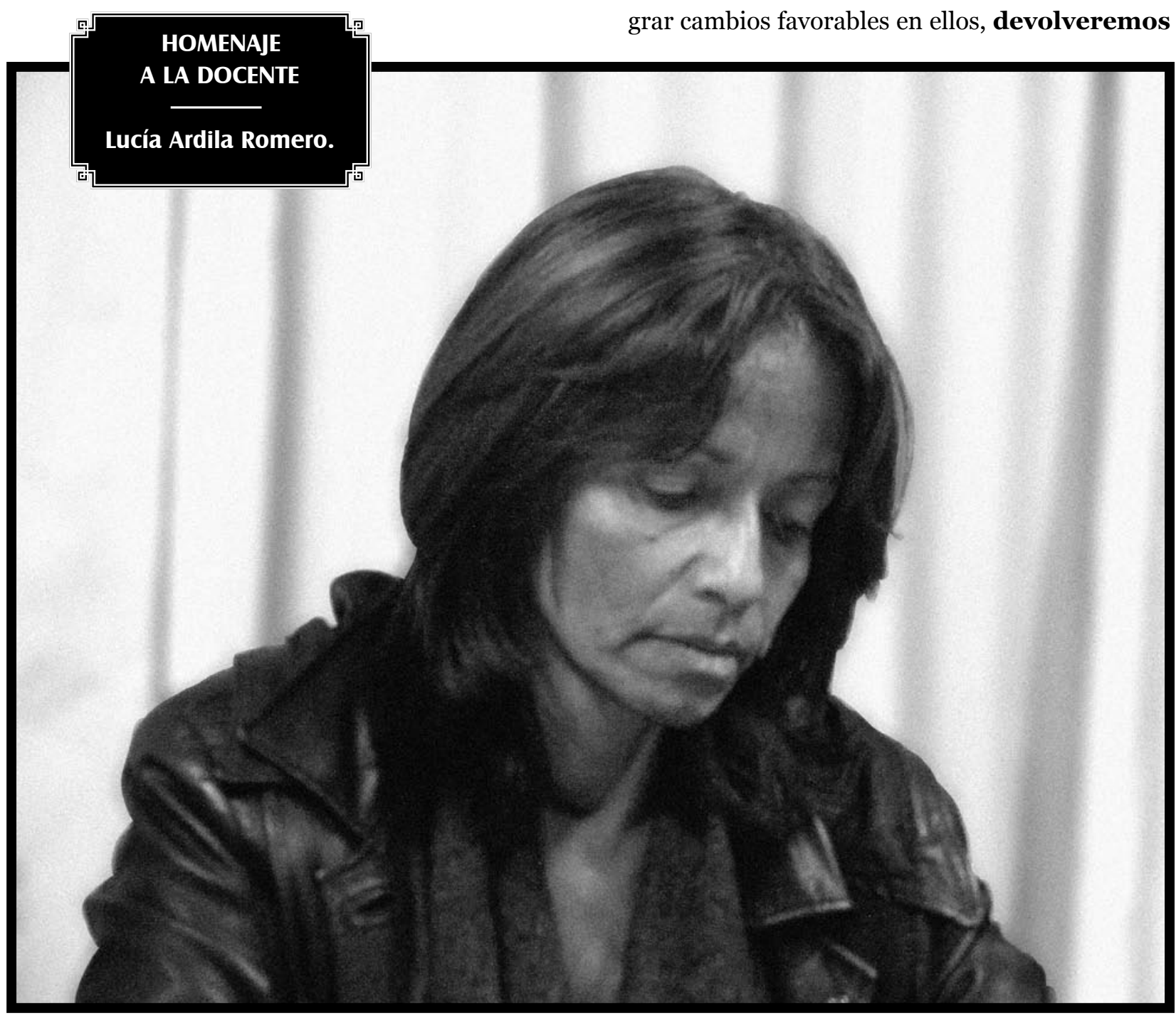

caso este ejercicio me ayudó de manera definitiva para clarificar el nublado panorama, que al inicio del ejercicio poseía.

Pero la práctica debía iniciarse y estudiantes y docente nos sumergimos poco a poco en la lectura, identificación y caracterización de realidades del contexto educativo, vimos; buscamos los apoyos teóricos que nos permitieran ampliar la mirada empírica y nos ayudaran a llenarnos de argumentos para la discusión, juzgamos; diseñamos estrategias que facilitaran la intervención frente a la problemática evidenciada, actuamos; esperamos que las estrategias diseñadas, se puedan implementar en los diferentes contextos, con el ánimo de lograr cambios favorables en ellos, devolveremos 
creativamente. Socializamos de manera continua los pasos dados y escuchamos las opiniones, sugerencias, aportes y argumentos de cada uno de nuestros compañeros, desde la aplicación del planteamiento del investigador-praxeólogo, propuesto por el padre Juliao:

- "Es sujeto tanto como objeto: es reflexivo, posee la cualidad de ser un objeto en sí mismo.

- Es relacional: está implicado en las interpretaciones de otros con quienes interactúa.

- Es comunicativo: interviene en unos intercambios simbólicos en los cuales el contenido de la comunicación está dirigido a otros y también a él mismo.

- Está gobernado por reglas y posee una cualidad estructural: asume roles, actúa en juegos, posee destrezas. ${ }^{27}$

Así fuimos construyendo, enriqueciendo y concretando el inmenso panorama de la praxeología, por ello ofrezco un sincero reconocimiento a los estudiantes que conformaban el VII semestre, de Investigación Educativa I en el municipio de Soacha, durante el segundo semestre del año lectivo 2005; fueron ellos los "conejillos de indias" en el laboratorio de mi formación frente a la identificación, caracterización e implementación del MODELO PRAXEOLÓGICO EN INVESTIGACIÓN. Hoy, en el ahora del aula de clase, porque nuevamente oriento este eje temático, tengo muchos más elementos construidos desde el saber de mis estudiantes y desde la lectura resignificada y ampliada de la propuesta explicitada por el padre Juliao.

Todos estos espacios de formación, práctica y reflexión me permiten afirmar que poseo muchos elementos de conceptualización frente al MODELO PRAXEOLÓGICO, pero también me hacen conciente del largo sendero que aún me falta por recorrer, hoy tengo un espacio más de crecimiento profesional en este ámbito, el grupo de Pedagogía, liderado por la maestra HILDA RUBIO e integrado por compañeros cuya experiencia y sabiduría espero aprovechar al máximo.

\section{MI HISTORIA DE VIDA EN LA PEDAGOGÍA}

POR: ROSA ISABEL GALVIS VARGAS ${ }^{28}$

$\mathrm{P}$ or lo general, las historias de vida deben iniciarse desde los primeros años y, poco a poco, ir acercándose al presente. Sin embargo, creo que mi historia de vida en la pedagogía la debo iniciar al contrario, es decir, desde el hoy. Y la razón es importante, porque hasta hace relativamente poco tiempo, descubrí mi gran atracción por ella y por la labor de ser maestro. Si retomo los planteamientos de la praxeología, la etapa del ver en este proceso se hizo evidente en mi vida en lo que respecta a la pedagogía, hasta tal punto que al momento de escribir estos párrafos, el ser maestro se ha convertido en mi vida, mi actividad central y principal.

Soy psicóloga de profesión, profundamente interesada por aportar al desarrollo de los procesos psicológicos y sociales de los seres humanos, preocupada por poder brindar elementos que permitan a las personas descubrir sus fortalezas y debilidades, para que, a partir de esta mirada un poco más consciente, puedan hacer una mejor construcción de sus propias vidas y de las personas que les rodean. Sin embargo, la vida misma me 
encauzó por el mundo de la pedagogía de una forma tan marcada, que en cada momento me siento más alejada de la psicología y más entregada a la misión como docente.

Este cambio de rumbo no puede haber sido fruto del azar; a veces utilizo la frase que suele ser aplicada en estos casos: "Dios nos pone donde nos necesita". Y es así como mi mayor experiencia la he adquirido en el campo de la docencia, principalmente en espacios de formación de docentes. Y aunque he incursionado por otros campos laborales, la vida misma me ha regresado al redil, el trabajo como maestra. Hoy en día, con una visión más clara de la vida y del mundo; con una mayor conciencia de lo que puedo aportar a otros, considero que el ser docente es una experiencia enriquecedora que permite crecer personal y profesionalmente, y a la vez aportar al crecimiento de otros.

Teniendo claro que los sucesos descritos no pueden ser sólo fruto del azar, el destino o la gracia de Dios, voy a realizar el recorrido normal de mi historia de vida regresando al pasado, con el fin de encontrar aquellos elementos que quizás se han ido perdiendo en el tiempo, pero que fueron fundamentales para poder comprender la realidad de hoy.

El recuerdo más lejano que tengo de ser maestra me lleva a mis cinco o seis años, cuando, en compañía de mis amiguitas del barrio donde vivía, organizábamos el salón de clase; obviamente yo era la maestra, asignaba tareas a cada uno de mis alumnos, les llamaba la atención para que hicieran silencio, llamaba lista y finalmente calificaba sus trabajos y evaluaciones. Los regañaba con firmeza al momento de no hacer sus deberes. Es decir, una verdadera maestra aplicando un modelo pedagógico tradicional.

De igual manera, al hacer este recorrido hacia el pasado, otra imagen que aparece nítida en mi mente es el verme enfrentada a escribir en el tablero en uno de los salones del colegio de propiedad de un tío, un día festivo de semana santa, época en la que solía reunirse la familia. Con tiza y borrador en mano, tratando de hacer la letra clara y sin torcerme. Esta es la hora en que aún sufro igual; nunca logré que la letra no se torciera; pero lo importante de dicho evento tiene que ver con la sensación que experimentaba de enfrentarme a ese tablero e imaginarme al frente de los estudiantes. Hoy en día, en ocasiones, al enfrentarme a los estudiantes, este es uno de los recuerdos que viene a mi mente, como si hubiese algo dentro de mí que me indicara que eso sería lo que yo tendría que hacer cuando grande. La sensación de la tiza en nuestras manos (desafortunadamente ausente), que muchos tuvimos la oportunidad de utilizar, necesariamente trae recuerdos de todo lo que pudimos dejar en nuestros estudiantes. La imagen de la tiza y el borrador, hoy marcador de acrílico y borrador, son elementos que necesariamente traen al presente todo lo que ha quedado escrito tanto en los tableros, sean de madera o acrílico, como en la vida y en la mente de los estudiantes.

En esta época temprana de infancia, que evoca lo vivido en los salones de clase de primaria, y posteriormente en la secundaria, la compleja adolescencia, surgen los personajes centrales: nuestros maestros, quienes de manera significativa dejaron huellas imborrables en nuestra formación como docentes.

Cuántas experiencias de formación nos llevaron a pensar en nunca llegar a realizar determinada acción en un salón de clase; o por el contrario, cuántas veces pensamos llegar a ser como alguno de nuestros maestros.

En este sentido, siempre ha sido de alta recordación mi profesora de segundo de primaria quien era excelente maestra, sin embargo, sus estrategias para manejo de grupo siempre las sentí contrarias a mi manera de ser y de pensar. Con sus estrategias pedagógicas lograba que un grupo de aproxi- 
madamente cuarenta niñas de seis o siete años, estuvieran a lo largo de una jornada de ocho horas, cuatro en la mañana y cuatro en la tarde, sentadas, juiciosas en sus respectivos lugares asignados, a punta de “deméritos", unos pequeños círculos colocados en una hoja cuadriculada tamaño oficio, que reposaba en la pared, pegada con pedazos de cinta, exactamente atrás del pupitre de la profesora. $\mathrm{Al}$ momento de realizar alguna estudiante una acción censurable, ella misma debía dibujar el "demérito”. Un conjunto de deméritos implicaba bajar la disciplina y la conducta, esto hacía que todas las niñas estuviéramos sentadas y juiciosas el mayor tiempo posible.

Siempre he pensado que su forma de manejar la disciplina no era la mejor. Sólo contaba con siete años, pero en ese momento yo sabía que debían existir otros mecanismos para tratar a los niños. Por supuesto, nunca he estado de acuerdo con estos radicalismos en la educación, hecho que me ha traído más de un problema con mis colegas por la manera como abordo los procesos de formación.

Con dicho régimen, lo que más recuerdo es mi clase de manualidades. Como excelente maestra que era, al iniciar una de sus actividades, nos motivó para la elaboración de una carpeta en crochet. Me sentí muy emocionada de poder llegar a elaborar una carpeta tan linda como la que había llevado de muestra la profesora. Era una carpeta blanca con unas puntas largas, e inmediatamente pensé en poder hacer una para mi mamá. Mi papá me compró un "hilo calabrés de color verde", que en este momento lo recuerdo y me parece espantoso. Bien, empieza el proceso de elaboración de la famosa carpeta, con la explicación de "las cadenetas, los monos y los medios monos". No me voy a extender más en esta descripción, el resultado de dicha experiencia fue el siguiente: mi profesora a lo largo del año, en la clase de costura, se dedicó a desbaratar lo que yo tejía durante la clase porque siempre estaba mal. Nunca me dijo cuál era mi error. No pude darle la carpeta a mi mamá, ni estuvo mi carpeta el día de las exposiciones. Lo mejor de esta experiencia pedagógica es que la profesora no logró que yo le cogiera aversión a las manualidades, por el contrario, más adelante yo descubrí cuál era mi error y elaboré muchas otras cosas en crochet.

La razón de traer al presente esta experiencia, al describir mi historia de vida en la pedagogía, es que tengo absolutamente claro que una posición radical y estricta en la educación nunca va a permitir que el docente se acerque a la verdadera realidad de su estudiante. No quiero decir con esto que no se deba corregir, esto no estaría en discusión. Lo importante es la actitud del docente, su acercamiento al estudiante, contar con sus necesidades y poder dar en lo posible aquellos elementos que le permitan satisfacerlas.

Siguiendo este recorrido por mis experiencias en la pedagogía, llego a mi primer encuentro con un grupo de estudiantes. Me encontraba cursando tercero de bachillerato, hoy en día octavo grado. Era un día cualquiera, en el que se realizaría una reunión extraordinaria de maestros, razón por la cual todos los maestros tendrían que dejar sus cursos solos. Con los estudiantes de secundaria no había problema, ya que se contaba con los monitores de curso. El problema surge con los cursos de preescolar y primaria. Por este motivo, la profesora de jardín, quien tenía un grupo de unos veinte pequeños, acude a nuestro salón en busca de un estudiante que pudiese acompañar a los pequeños durante el tiempo que durase la reunión. Yo me ofrecí como voluntaria. Al llegar al salón la profesora me presenta con los niños, da las explicaciones del caso y se va. Me he quedado sola con ellos y no tenía la menor idea de qué actividad desarrollar.

En este momento, este relato me permite ver con mayor claridad la incidencia de nuestros principios, valores y formas de abordar el mundo al momento de afrontar los procesos de formación en educación. Desde aquel 
momento, en el que no contaba con ningún tipo de formación pedagógica, lo primero que pensé fue en preguntar a los niños: ¿qué quieren hacer? A coro me respondieron: ¡Pintar con témperas!

Me puse a la labor, sin ninguna clase de técnica, ni pasos, en la tarea de brindarles los materiales necesarios para que ellos pintaran con témperas. Estoy segura que ellos estuvieron ocupados y contentos. Quizá desarrollaron algunos procesos, así fuese únicamente motricidad fina. Se pintaron sus delantales, mancharon las mesas. Al llegar la maestra titular, quedó un tanto preocupada por el desorden que formamos los niños y yo.

Un hallazgo importante al traer esta experiencia pedagógica a mi historia de vida, se relaciona con la poca conciencia que poseía respecto a mi interés por la pedagogía. Desde esa temprana edad, había algo en mi interior que me invitaba a orientarme por la educación como actividad central. Es una lástima que los procesos de orientación profesional no propicien en los estudiantes dichos reconocimientos que permitan mayores luces para esa formación profesional.

Otro aspecto relevante, que surge en dicho relato y reafirma lo propuesto atrás, tiene que ver con mi postura frente a los estudiantes. Estoy convencida de que debo partir de su realidad, de sus necesidades, de aquello que les motiva, totalmente consciente de que tengo que "ponerme en sus zapatos", para poder responder a sus verdaderas necesidades personales y académicas. Desde la praxeología, lo asumo como el ver, que me va a permitir la búsqueda de apoyos teóricos que me brinden las suficientes herramientas para generar cambios cualitativos como personas y en su formación escolar y/o académica.

Al hablar de orientación profesional, siento una profunda tristeza. Y lo hablo principalmente como profesional de la psicología. No me siento inconforme con la carrera elegida, pero qué importante hubiese sido haber contado con una mejor orientación en mi elección de carrera.
Miro hacia atrás y pienso: iqué rico hubiese sido haber recibido una formación como normalista! O haber elegido una licenciatura en química, en sociales, en idiomas o humanidades. Lo positivo: no me alejé del ámbito educativo con mi elección. Termino el bachillerato e ingreso a estudiar psicología.

A lo largo de mi proceso de formación como profesional, me incliné hacia el área de la psicología clínica, con miras a poder aportar a la reducción del sufrimiento de las personas con problemas mentales y emocionales. Poco interés hacia el área de la psicología educativa. Sin embargo, como lo expresaba al iniciar este escrito, la vida nos lleva por donde debemos ir.

Al terminar mis estudios universitarios, todas mis experiencias laborales me llevaron por el campo de la educación, a lugares donde aprendí a ser maestra.

Mi primera experiencia laboral en educación la tuve cuando decidí abrir un jardín infantil en sociedad con una compañera. La institución educativa vivió un año, ya que como suele suceder con las sociedades, ésta se disolvió, con la consiguiente revisión del inventario y la equitativa repartición de arañas de juguete, títeres, sillas y mesas de madera, cuentos infantiles y demás artículos que no alcanzan a dimensionar la muerte de un sueño importante. Es trascendente hacer referencia a este evento, ya que esta idea a quien llenó de mayor alegría fue a mi mamá, quien siempre había soñado con ser maestra. Desafortunadamente, ella murió al poco tiempo de morir el jardín. El consuelo que queda es que ella muere pensando que su hija estaba trabajando en lo que ella siempre había soñado.

$\mathrm{Y}$ al respecto se puede considerar la idea de que el ser maestro lo llevamos en los genes. ¿Será que se puede hablar de un gen para la educación, un gen para ser maestro? ¿Un gen que no todas las personas lo poseen? Sería para reflexionarlo. Lo cierto es 
que este amor por la pedagogía se hace evidente en cada día de nuestro actuar como maestros.

En aquella experiencia del jardín infantil, comencé a reconocer una "magia" en mi interior que hacía que los pequeños se sintieran a gusto trabajando conmigo. Y en ese compartir, cuando juego y trabajo con ellos, voy siendo niña y voy reafirmando nuevamente mi postura tradicional, tratar de ser niña para poderlos comprender y precisar sus necesidades. $Y$ esto ha venido siendo evidente con el transcurrir de los años, no importa la población estudiantil con quien se labore. Ponerme en su lugar para poder brindarles lo que realmente necesitan.

Sobreviene un tiempo que mi padre lo llamaba "de piojo”, es decir, no conseguía trabajo. Después del tradicional envío de muchas hojas de vida, una amiga cercana me sugiere llevar una a la Normal de Nuestra Señora de la Paz, en el año 1988. Esa experiencia va a ser definitiva para lograr un proceso de formación teórico-práctico en el campo de la educación. Ingreso a desempeñar el cargo de orientadora de secundaria. Posteriormente crean el cargo de orientación de primaria y me es asignado. $\mathrm{Al}$ año siguiente ingreso al Centro Educativo de Nuestra Señora de la Paz, donde laboro a lo largo de 16 años. En este espacio logro apropiarme y reflexionar profundamente acerca de lo que significa la labor del maestro. En mi desempeño como orientadora de secundaria, donde paralelamente debo apropiarme y estar a cargo de espacios de formación, es decir, horas clase, logro mi formación como docente. Es allí donde aprendo a elaborar planeaciones de clase, llevar procesos de evaluación, diligenciamiento de diarios de experiencias pedagógicas, entre muchas cosas más. Todo esto a la luz de un modelo de formación en pastoral, donde se parte de un ver, juzgar y actuar.

Pasan 14 años, cuando tengo la fortuna de acercarme a la experiencia pedagógica con Uniminuto. Llego a la institución invitada a participar en un proceso de formación con estudiantes del Programa Nacional de Reincorporación a la vida civil y dejación de armas del Ministerio del Interior y de Justicia. Allí tengo la posibilidad de acercarme a los jóvenes y jovencitas que han optado por iniciar una nueva vida. Y es aquí, en esta experiencia, donde nuevamente descubro cómo mi forma de abordar los procesos educativos, se hace evidente. En dicho proceso, el cual al día de hoy, cumple 3 años, siempre he tratado de ponerme en su lugar, con sus necesidades, inquietudes, temores, expectativas. No ha sido fácil, pero es una experiencia que me ha dejado profundas enseñanzas, a nivel personal y profesional, tanto en el campo de la psicología como en el de la pedagogía.

$\mathrm{Al}$ inicio de esta experiencia, los docentes que afrontamos dicho reto, al enfrentarnos con un programa que no tenía experiencias previas, tuvimos que vivir la etapa del ver que nos sugiere la praxeología; en esas experiencias de observación día a día, fuimos descubriendo la mejor manera de acercarnos a una población de jóvenes con profundas necesidades académicas, formativas y afectivas. La formación teórica, así como la experiencia adquirida previamente,

LA REALIDAD DEL ESTUDIANTE, SU NECESIDAD, ES LO FUNDAMENTAL; ASÍ TENGA CINCO AÑOS O CINCUENTA; SEA EN UN AULA REGULAR O EN UNA PRISIÓN; SEA ESTUDIANTE DE SECUNDARIA O DE UNIVERSIDAD, LO IMPORTANTE ES BRINDARLE LO QUE REALMENTE NECESITA 
enriquecida con las posturas teóricas de pedagogos y psicólogos, permitieron que fuéramos conformando una propuesta pedagógica que nos brindó la posibilidad de aportar a la promoción de tres grupos de egresados como bachilleres. A lo largo de ese actuar, al aplicar diversas estrategias que tenían como finalidad el poder brindar diversos elementos que aportaran de manera significativa a la formación de nuestros estudiantes, logré importantes aprendizajes tanto en lo personal como en lo profesional. En lo que concierne al ámbito educativo, nuevamente me encuentro como la docente que trata de colocarse en el lugar del estudiante; en algún momento tuve la intención de tomar una postura estricta y rígida que al instante tuvo que ser modificada por una postura auténtica, acorde con mi personalidad. Asumir una postura comprensiva, de diálogo y escucha, esa considero que fue la clave para lograr progresos importantes en la relación maestro-estudiante, que llegaron a ser definitivos para los logros alcanzados en este proceso.

Paralelamente a dicha experiencia, una vez más me encuentro con los momentos de ver, juzgar, actuar, en los procesos pedagógicos de la Facultad de Educación. Sin embargo, surge otro que para mí es desconocido, la devolución creativa. Me encuentro en una etapa de apropiación de este último elemento dentro del proceso praxeológico, sin embargo, al ver el proceso que se ha llevado a cabo con los jóvenes del Programa de Reincorporación a la Vida Civil y Dejación de Armas, siento que el momento de la devolución creativa se hace evidente, cuando se logra percibir una trasformación cualitativa en algunos de los jóvenes que desarrollan con nosotros la totalidad de la experiencia.

Al entrar a formar parte de la Facultad de Educación, acompañando el proceso de práctica profesional, me doy cuenta de que es una experiencia caracterizada por su alto nivel de formación académica y profesional. A nivel personal, lo primero que viene a mi mente es el rostro de una compañera, quien me expresa su alegría al tener conocimiento de mi ingreso a la Facultad, y cómo su sonrisa se va transformando en preocupación al saber que voy a ser docente de práctica profesional, espacio que hasta ese momento había generado bastantes dificultades a la Facultad. Desde ese día al presente, han transcurrido dos años, a lo largo de los cuales se han tenido que abordar las posturas de los estudiantes, con el fin de convencerlos de las bondades del proceso de formación seria y responsable de la práctica profesional. Los logros que se han obtenido han sido importantes, porque se ha desarrollado un trabajo comprometido y en equipo por parte de los docentes que hemos formado parte de dicha experiencia. Las enseñanzas han sido múltiples. Y al llegar al día de hoy en esta historia de vida en el ámbito de la educación y la pedagogía, lo que prevalece y resalto de manera notable es la claridad que he alcanzado respecto a mi postura frente a los procesos de formación. No importan las críticas, ni los cuestionamientos, estoy convencida de que la posición del educador debe ser una postura absolutamente humana, con toda la posibilidad de ponerse en el lugar del otro.

La realidad del estudiante, su necesidad, es lo fundamental; así tenga nuestro estudiante cinco años o cincuenta; sea en un aula regular o en una prisión; sea estudiante de secundaria o de universidad, lo importante es brindarle lo que realmente necesita; en ocasiones su necesidad será de conocimientos, de desarrollo de habilidades cognitivas o posiblemente la necesidad de un encuentro interpersonal que le permita descubrir sus potencialidades, su sentido de vida, o quizá orientar su futuro.

Termino esta historia de vida pedagógica siendo reiterativa al plantear mi postura frente a los procesos disciplinarios: las posturas rígidas y estrictas en los procesos formativos en contra de las posturas un tanto flexibles que tienen como finalidad mantener una actitud de diálogo y comunicación. Para mí esta es la discusión. El tomar conciencia acerca de esta última postura es algo altamente significativo al finalizar este escrito. 
NOTAS

1 Los docentes participantes y autores de las historias de vida son: Lucía Árdila Romero, Rosa Isabel Galvis, Carlos González Pulido, Roberto Herrera Correa, Francisco de Asís Perea Mosquera, Simón Pérez Herrera, Olga Ramírez Torres, Hilda Rubio González, Yolanda Villarroel Coronado.

2 El Plan de Estudios de los programas de Licenciaturas que lidera la Facultad de Educación están estructurados por áreas: Pedagogía, Disciplinar y Macrocurrículo. Las áreas de Pedagogía y Macrocurrículo son comunes a todas las licenciaturas; el área Disciplinar se compone de los espacios académicos que identifican cada uno de los énfasis: Informática, Humanidades y Lengua Castellana, Tecnología e Informática, Artística y Educación Religiosa.

3 Elaboraciones que son parte de la producción colectiva con maestros de la Facultad de Educación, liderada por el padre Carlos Germán Juliao Vargas y que dieron origen a la investigación cofinanciada por COLCIENCIAS, BID y Uniminuto, cuyo producto se publicó en el libro Construcción de un modelo pedagógico alternativo a partir de la Praxeología, 2002. Cf. Juliao, Carlos. La praxeología: Una alternativa de la Práctica. Uniminuto. 2003.

4 Las historias de vida de los maestros(as), ocho en total, pues se presentó una deserción, se anexan como parte del éste artículo y corresponden a: Maestra Lucía Ardila Romero: Aproximación a la praxeología. Reflexiones Personales.

Maestra Rosa Isabel Galvis Vargas: Mi historia de Vida en la Pedagogía. Maestro Carlos A. González Pulido: La Praxeología en el aula de clase. Maestro Roberto Herrera Correa: Formación Docente y Praxeología Pedagógica. Maestra Hilda M. Rubio González: Un recorrido por la incertidumbre. Maestro Francisco de Asis Perea Mosquera: La historia de vida como una forma de comprender la docencia.

Maestro, P. Simón Pérez Herrera, cjm: Una historia de vida y un ejercicio docente leído desde la praxeología.

Maestra Yolanda Villarroel Coronado: Y las Flores fueron testigo.

5 Licenciado en estudios en Ciencias Sociales. Universidad Pedagógica Nacional. Especialista en Educación Filosófica Colombiana. Universidad Santo Tomás Especialista en Diseño de Ambientes de Aprendizaje. Uniminuto. Magíster en Educación. Universidad de la Sabana. Coordinador Licenciatura Básica con énfasis en Educación Religiosa. Docente Facultad de Educación. Uniminuto.

6 Licenciado en Química y Biología. Universidad Tecnológica del Chocó. Diego León Córdoba.

Magíster en Docencia de la Química. Univesidad Pedagógica Nacional. Docente de pregrado en la Corporación Universitaria Minuto de Dios y de la Maestría en Educación de la Universidad Pedagógica Nacional.

7 JULIAO, Vargas Carlos G., cjm. La Praxeología: una teoría de la práctica. Uniminuto, Bogotá, 2002.

8 Este era el sobrenombre.

9 Término que se usa en el Chocó para denominar a una persona que se pega hablando, tatareto o tartamudo como lo denominan en el interior del país.

10 Expresión chocoana del campo que significa experticia o pericia.

11 Término utilizado par decir que no es buen combustible, por poseer internamente cápsulas hídricas.

12 DE FRIDEMAN, S. Nina y PATIÑO, Roselli Carlos. Lengua y Sociedad en el Palenque de San Basilio. Instituto Caro y Cuervo, Bogota, 1983.
13 Antiguamente se creía en el Chocó que si a una persona al nacer y en e proceso de cura del cordón umbilical se le añadía polvo de algún animal, asimilaba algunas características de éste como fortaleza si lo ombligaban con tigre, movedizo si lo ombligaban con mico, etc. Este personaje fue ombligado con anguila.

14 Licenciado en Teología. Universidad Javeriana. Sacerdote Eudista.

Especialista en Gerencia Social. Uniminuto.

Magíster en Administración y Supervisión Educativa. Universidad Javeriana.

Docente Tiempo completo Facultad de Educación Uniminuto.

15 Licenciado en Psicocología y Pedagogía. Universidad Pedagógica Nacional.

Especialista en Procesos Lecto-escriturales. Uniminuto.

Docente de medio tiempo Facultad de Educación Uniminuto.

rohec0157@hotmail.com

16 Licenciada en Psicopedagogía. Universidad Externado de Colombia.

Especialista en Desarrollo Infantil con énfasis en niños en condiciones de Alto

Riesgo. Universidad INCCA.

Secretaría Académica. Facultad de Educación. Uniminuto.

Docente Facultad de Educación Uniminuto.

Docente Facultad de Educación Fundación Universitaria Los Libertadores. yvillarroel@uniminuto.edu

17 "El profesor, ese desconocido" Cuadernos de pedagogía \#661 Julio-agosto 1.988 Pg.5.

18 Ibídem, pág. 5 .

19 lbídem, pág. 5 .

20 lbídem, pág. 5 .

21 lbídem., pág. 5 .

22 Introducción a la pedagogía S.P. Baranov. Pg. 7. El pueblo y Educación HabanaCuba 1.989.

23 Licenciada en Básica Primaria. Instituto Técnico Universitario de Cundinamarca ITUC.

Especialista en Educación y Orientación Sexual. Fundación Universitaria Manuela Beltrán.

Magíster en Investigación Educativa. Instituto Central de Ciencias Pedagógicas

Cuba.

Candidata a doctora en Ciencias Pedagógicas. Universidad Nacional Agraria de la

Habana.

Docente medio tiempo Facultad de Educación Uniminuto.

Docente Universidad Libre.

moongreen31@yahoo.es

24 BERMÚDEZ BALAGUERA, Rogelio. Las leyes del Aprendizaje. La Habana. Cuba. Ed. Pueblo. 2005

25 SACRISTÁN Manuel, citado por LÓPEZ ARNAL Salvador. En Torno a la Dialéctica. La Insignia. España. 2005

26 lbíd.

27 JULIAO VARGAS, Carlos. La Praxeología una Teoría de la Práctica. Universidad Minuto de Dios. Bogotá. 2002.

28 Psicóloga. Universidad INCCA DE COLOMBIA. Docente de tiempo completo de la Facultad de Educación. Uniminuto. rosisa41@hotmail.com 